\title{
Sustaining Collusion in Growing Markets
}

\author{
HÉLDER VASCONCELOS \\ Universidade Católica Portuguesa (CEGE) \\ Rua Diogo Botelho, 1327 \\ 4169-005 Porto, Portugal \\ hvasconcelos@porto.ucp.pt
}

The impact of demand growth on the collusion possibilities is investigated in a Cournot supergame where market growth may trigger future entry and the collusive agreement is enforced by the most profitable 'grim trigger strategies' available. It is shown that even in situations where perfect collusion can be sustained after entry, coping with a potential entrant in a market which is growing over time may completely undermine any pre-entry collusive plans of the incumbent firms. This is because, before entry, a deviation and the following punishment phase may become more attractive thanks to their additional effect in terms of delaying entry.

\section{Introduction}

A standard result in supergame theoretic models assessing the factors that influence collusion is that demand growth facilitates collusion. ${ }^{1}$ The intuition is very simple. The higher the rate of demand growth, the higher is the importance of future profits from collusion relative to the current gain from deviating. This is the so called pro-collusive intrinsic effect of demand growth on collusion.

An important problem regarding this standard result, however, is that it contrasts with the views expressed by the European Commission (EC) and the Court of First Instance (CFI) when analyzing merger

I thank an anonymous coeditor of this Journal, two anonymous referees, Andrea Amelio, Pierpaolo Battigalli, Joe Harrington, Xavier Mas, Massimo Motta, Lars Persson, Patrick Rey, Robert Rothschild, Lucy White, and seminar participants at the 2005 EARIE Conference (Porto), the 2006 IIOC (Boston), European University Institute, Faculdade de Economia do Porto and at the Portuguese Competition Authority for their valuable comments on earlier versions of this paper. Special thanks are due to Karl Schlag for many insightful discussions and precious help in the more technical parts of the paper. All errors remain my own responsibility. Part of the research reported here was carried out while I was visiting the European University Institute (Florence). I express my appreciation for their hospitality. An earlier version of this paper was awarded with the Young Economist's Prize at the 2005 EARIE Conference.

1. See, for instance, Motta (2004, pp. 163-164) and Tirole (1988, p. 250). 
cases. Both the EC and the CFI usually interpret demand growth as a factor hindering collusion. The widely discussed Airtours/First Choice merger is a case in point. ${ }^{2}$ One interesting feature of this case is that, even though both the EC and the CFI agreed on their view of demand growth's effect (which contrasts with the view of standard literature on the topic), they disagreed about the extent of demand growth. In 1999, the EC prohibited the merger between Airtours and First Choice claiming that the proposed merger would have created a situation of joint dominance by Airtours / First Choice and two other competitors in the UK short-haul package holiday market. ${ }^{3}$ However, in June 2002 the CFI overturned the EC decision. ${ }^{4}$

One of the reasons that led the CFI to annul the EC decision was that the EC analysis of demand growth was considered to be flawed. While the EC included low demand growth and substantial barriers to market entry in the list of market characteristics which would facilitate joint dominance, ${ }^{5}$ the CFI found that: (i) the market was one of strong demand growth, ${ }^{6}$ (ii) there are no significant barriers to market entry; ${ }^{7}$ and (iii) the EC had underestimated the extent to which entry by new firms (especially small UK tour operators or foreign tour operators) might be feasible. ${ }^{8}$ On this basis, the CFI concluded that "the lack of barriers to market entry is likely to allow potential competitors to gain access to, and offer their products on, the relevant market and, therefore, to take fast and effective action in the event of the large tour operators ... give rise to a situation of under-supply." (paragraph 269 of the CFI Judgement). ${ }^{9,10}$

2. Airtours/First Choice, Case IV/M. 1524 (Decision of September 22, 1999).

3. Joint dominance effects of mergers refers to the possibility that firms reach a collusive agreement after the merger.

4. Airtours p/c v. Commission of the European Communities, Case T-342/99 (June 6, 2002).

5. See paragraphs 121 and 126 of the CFI Judgement.

6. In the CFI Judgment it is stated that "the market had been marked by a clear tendency to considerable growth over the last decade... In that context of growth,... the Commission was not entitled to conclude that the market development was characterized by low growth, which was, in this instance, a factor conducive to the creation of a collective dominant position by the three remaining large tour operators." (paragraph 133).

7. See paragraphs 98 and 263 of the CFI Judgement.

8. See, for instance, paragraphs 215 and 266 of the CFI Judgement.

9. According to Garrod et al. (2002), the CFI Decision on the Airtours case provides considerable guidance to merging companies as to the facts that need to be developed to avoid the application of the joint dominance doctrine. "Specifically, facts should be developed to establish ... that demand in the market is increasing-which should give members of any alleged oligopoly the incentive to cheat and which would encourage new entry." (p. 3)

10. Ivaldi et al. (2003) point out that another example illustrating the divergence between the conclusions of the literature focusing on the intrinsic pro-collusive effect of demand growth and the opinions expressed by the EC is given by the recent guidelines for market analysis and the assessment of significant market power in electronic communications markets. In fact, in Annex II of the EC Decision 676/2002/EC (OJ L 108, of $24 / 04 / 2002$ ) it is stated that " $[t]$ wo or more undertakings can be found in a joint dominant 
The motivation offered by the CFI for why increasing demand without (significant) barriers to entry hinders collusion appears to be in line with the views expressed by Ivaldi et al. (2003). According to these authors, one possible reason for this discrepancy between economic theory and competition practice is that previous literature analyzing demand growth effects on collusion has relied on an assumption that is clearly unwarranted. Specifically, it "assumes that the number of market participants remains fixed despite market growth, while in practice, entry may be easier in growing markets" (p. 28). Indeed, growing markets are likely to allow entry by new firms which should hinder collusion. As a result, it seems important to try and understand whether the detrimental impact of entry stimulated by market growth on collusion can outweigh the intrinsic pro-collusive effect of market growth.

The current paper has taken seriously this argument by considering a simple model in which there are two incumbents and one potential entrant in a market which is growing over time. Firms engage in an infinite horizon dynamic game of quantity competition and the entrant must pay a fixed (sunk) cost upon entering the market. The main goal of the analysis is to characterize the maximal level of collusion the incumbents and the entrant can achieve using "grim trigger strategies" to punish deviations (Friedman (1971)).

Within this framework, we start by analyzing firms' optimal behavior after entry and derive the optimal entry date. It is shown that entry always occurs in equilibrium if sunk entry costs are moderate.

We then turn to the analysis of the pre-entry behavior and characterize the relationship between the market growth rate and the level of collusion sustainable before entry. We find that when the market growth is extremely fast, perfect collusion can be sustained both after and before entry. The pro-collusive intrinsic effect of (the very fast) demand growth turns out to be sufficiently strong to more than compensate for the impact of entry which is likely to be stimulated by demand growth on pre-entry collusion. However, and perhaps more importantly, it is also shown that even in situations where demand growth is sufficiently strong so that perfect collusion can be sustained (by three firms) after entry takes place, it may be the case that no collusion can be sustained before entry by the two incumbent firms. Coping with a potential entrant in a market which is growing over time may completely undermine pre-entry collusive plans. The reason is that in the period of time just before the optimal entry date along the collusive path (and, by backward induction, in all previous periods) firms might not resist the temptation

position ... if ... the market satisfies a number of appropriate characteristics, in particular in terms of ... stagnant or moderate growth on the demand side." 
to deviate because (i) a deviation delays entry (which occurs later on along the punishment path); and (ii) the first phase of the punishment works like an extension of the deviation phase because the Cournot duopoly profits earned by each incumbent firm during that phase exceed the most collusive individual profits when there are three firms in the industry. This result, therefore, is important from a policy point of view because it provides a possible theoretical rationale for why the EC and the CFI usually consider that higher demand growth is a factor that makes collusion less of a concern. In addition, it seems consistent with the Airtours/First Choice merger case mentioned above because, as stated in a recent article in The Economist,"11 "the courts disagreed [with the EC prohibition decision], ruling that it is difficult to... discipline cheating, and impossible to prevent smaller competitors or new entrants from expanding supply and spoiling the incumbent's game."

To the best of our knowledge, the only paper that studies the impact of demand growth on collusion when entry is feasible is Capuano (2002). There exist, however, three major differences between Capuano's framework and the setting used in this paper. First, the focus of Capuano's paper is on perfect collusion sustainability, while the present paper is also concerned with the characterization of the maximal degree of collusion consistent with equilibrium (which may be something less than perfect collusion) and how this maximal degree changes with the rate of market growth. Second, Capuano's paper is only able to provide a limited result regarding the equilibria prior to entry. ${ }^{12}$ In contrast, and given that pre-entry behavior seems to be the most relevant for policy discussion, most of the focus of the current paper is on the characterization of the pre-entry equilibria. Lastly, while in Capuano's model entry is assumed to occur as soon as the entrant expects a positive NPV of profits, in the current paper entry timing is optimal (and, under some conditions, may be delayed beyond this point).

Previous research on quantity setting supergames has investigated the degree of collusion which can be achieved when the number of market participants is endogenously derived from a free-entry condition. Different types of incumbent firms' responses to entry have been studied. A first possibility is that incumbents use punishment schemes of the type which has been characterized by Abreu (1986) to make entry unprofitable and support the joint profit maximum (see, for instance,

11. Silent Orchestration, The Economist, March 31, 2007, at p. 84.

12. Moreover, in Capuano's paper it is implicitly assumed that the satisfaction of the incentive compatibility constraint in the very first period of the game is sufficient for preentry incentive compatibility while the current paper shows that this is an indefensible assumption. 
Harrington (1989)). ${ }^{13}$ A second possibility is studied by Harrington (1991). This paper considers the situation in which colluding firms, when facing an entrant, either include the new firm in the collusive agreement immediately upon entry or forego collusion and trigger to single-shot Cournot equilibrium output levels. Another plausible response to entry has been proposed by Friedman and Thisse (1994). Their paper considers a type of collusion which is not generous to entrants. Entrants' profits are in the first period after entry a little better than those corresponding to discounted single-shot Cournot equilibrium. Their output then increases gradually over time until eventually the entrants become full partners in the collusive scheme. ${ }^{14}$ However, all these models, contrary to the present paper, assume constant demand over time and thus do not model the process by which entry is triggered in the long-run.

The rest of the paper is organized as follows. Section 2 describes the basic model. Section 3 briefly discusses the case in which entry costs are prohibitive and, therefore, there is no entry triggered by market growth. In Section 4, we analyze firms' optimal behavior ex post entry and characterize the optimal entry date (along the collusive path) when entry costs are not prohibitive. Section 5 will focus on how market growth affects the level of collusion that can be sustained before entry by the incumbent firms. Section 6 studies two possible extensions of the basic model. In particular, it discusses the case in which there are two potential entrants and analyzes whether partial collusion between the two incumbent firms is feasible in this setting. Finally, Section 7 offers some concluding comments.

\section{Basic Model}

Consider an industry in which there are two incumbents and one potential entrant. Firms play an infinite horizon game and in each period of time all active firms (i.e., the two incumbents and the entrant, in

13. If the stage game is Bertrand type and firms face symmetric and constant marginal costs, then entry can be deterred by the threat of Nash-reversion. Entry never occurs, unless the entrant anticipates that it will be accommodated in a more inclusive collusive agreement.

14. There is also a strand in the literature, staring with the seminal study of Green and Porter (1984), that has formalized the issue of secrete price cutting in a setting where: (i) demand is subject to exogenous shocks; and (ii) firms' quantities are private information but the random market price is publicly observed (imperfect monitoring). Contrary to perfect observability models of collusion where price wars are a threat that never occurs in equilibrium, the Green and Porter's (1984) model does predict the existence of periodic price wars. These price wars are, however, involuntary in the sense that they are triggered by states of low demand and not by defection (which does not occur in equilibrium). This model has been extended by Vasconcelos (2004) to consider the possibility of entry, allowing the incumbent firms to either punish or accommodate entry when it occurs. 
case it has already entered) simultaneously choose an output rate. The potential entrant has to decide when to enter the industry (if it enters at all). A one-time (sunk) entry cost $K, K \geq 0$, has to be incurred if entry takes place. ${ }^{15}$ Active firms offer a homogeneous product and production is assumed to be costless for all firms. The payoff function of a given firm is given by the sum of discounted profits, where profits are received at the end of each period, and the common discount factor is $\delta \in(0,1)$.

Assume that, in each period of time $t=0,1,2, \ldots$, market demand is given by $Q_{t}=\left(1-p_{t}\right) \mu^{t}$, where $p_{t}$ denotes the market price in period $t$ and $\mu>1$ is the parameter measuring demand growth. Hence, demand is growing steadily at rate $(\mu-1) .{ }^{16}$ Assume also that $\mu \delta<1 .{ }^{17}$

Under this set of assumptions, it is easy to show that the profits in a Cournot-Nash equilibrium for the single-period game played in period $t$ when there are $n$ firms in the industry are given by ${ }^{18}$

$\pi_{t}^{c}(n)=\frac{\mu^{t}}{(n+1)^{2}}$.

The monopoly profit in a given period $t$ is, therefore, $\pi_{t}^{m}=\pi_{t}^{c}(1)$,

$\pi_{t}^{m}=\frac{\mu^{t}}{4}$.

We will focus on a particular class of subgame perfect Nash equilibria (SPE) of the infinitely repeated game, which we call Most Collusive Trigger Strategy Equilibrium with Entry (MCTSEE). A MCTSEE is a SPE where active firms and the potential entrant follow the following strategies, respectively. Starting from period 0 , active firms will produce in any period $t \in\{0,1,2, \ldots\}$ the best collusive sustainable output consistent with the number of active firms in the market and also with the discount factor $\delta>0 .{ }^{19}$ This most collusive output rate will continue to be produced as long as no other active firm has deviated from the collusive path. In the event of a deviation, active firms permanently

15. Because this is a unique cost to the potential entrant, the size of $K$ can be interpreted as the "height" of (exogenous) barriers.

16. As pointed out by Tirole (1988), a model of this kind describes the same type of situation discussed by Rotemberg and Saloner (1986). The only differences are that, on the one hand, shocks are perfectly anticipated and there is a trend, on the other.

17. Note that $\mu \delta$ can be interpreted as an adjusted discount factor which accounts for market growth.

18. See Appendix A.

19. The continuity offered by the Cournot model allows us to focus the analysis on the characterization of the maximal degree of collusion consistent with equilibrium and which may be something less than perfect collusion. In addition, it is worth remarking that the Cournot model employed here offers a richness of comparative statics results that do not obtain under classical Bertrand competition. It is well known that with this alternative mode of competition, as long as the discount factor is above a critical threshold value, then any collusive price can be sustained (even the monopoly price). 
revert to the single-period Nash equilibrium (Friedman (1971)). ${ }^{20}$ The potential entrant will enter the industry in the period in which the NPV of its expected post entry profits is maximal. In case entry occurs, the potential entrant becomes an active firm and should, therefore, follow the strategy of an active firm for the remainder of the horizon.

\section{Incumbents Õ Reaction to Entry}

Before proceeding with the analysis, however, it is important to explain why we consider that the incumbents incorporate the entrant in a more inclusive agreement as soon as it enters rather than credibly threaten the entrant to revert to an equilibrium in which the entrant would be minmaxed so as to deter entry. ${ }^{21}$ Three kinds of arguments lead us to believe that the latter type of behavior by the incumbent firms is unlikely in many circumstances. First, as was highlighted by Besanko et al. (2004, p. 302), "accommodated entry is typical in markets with growing demand." Second, collusion is illegal and firms in the industry are certainly aware whenever self-enforcing agreements are being implemented. Hence, an entrant which is minmaxed by colluding incumbent firms will have very strong incentives to denounce the existence of the collusive agreement to the antitrust authorities so as to earn a per-period Cournot individual profit rather than its zero minmax payoff. ${ }^{22}$ Lastly, as pointed out by Friedman and Thisse (1994), entry is in many industries a reality incumbent firms have to live with. Therefore, in these situations, "intuition suggests that the incumbent firms might prefer to recontract and include the entrant into a revamped collusive agreement" (p. 272).

20. It is important to explain at this point why we consider Cournot-Nash reversion while it is well known that, for quantity-setting supergames, Abreu (1986) has characterized a class of more sophisticated and more severe punishments than standard "grim trigger strategies." First, as pointed out by Harrington (1991, p. 1089) "it is quite natural to think of a punishment strategy as being an industry norm with respect to firm conduct... Furthermore, once a norm is in place, firms may be hesitant to change it... Thus, even though the norm might not be the best in some sense (for example, it might not be a most severe punishment strategy), firms might seem choose to maintain it if it seems to work. In light of this interpretation of a punishment strategy, it seems plausible that the grim trigger strategy would be a commonly used norm." Second, the use of standard trigger strategies has the advantage of requiring simple calculations and also of being easily understood by market participants.

21. Minmaxing an entrant consists in treating the entrant as a defector from the collusive agreement (say, because the potential entrant was supposed to produce zero along the equilibrium output path). Because in our setting the minmax payoff is zero independently of the demand level, a firm's security level is a discounted payoff also equal to zero. Hence, if for some (sufficiently high) values of the discount factor security level punishment can be supported as a SPE, then by credibly threaten the entrant to revert to the equilibrium where it obtains zero profit as a continuation payoff, entry could be prevented.

22. Whistle-blowing mechanisms to deter collusion have been studied in detail by Motta and Polo (2003), Harrington (2008), and Aubert et al. (2006). 


\section{A Benchmark Case: Prohibitive Entry Barriers}

In this section, we briefly consider the benchmark case in which the number of market participants cannot be affected by market growth because $K$ is assumed to be prohibitive (e.g., because of needed patents).

Let $\tilde{q}_{t} \equiv q_{t} \mu^{t}$ denote the individual collusive output in period $t$ when there are $n$ firms in the market, where $q_{t} \in\left[\frac{1}{2 n}, \frac{1}{n+1}\right){ }^{23}$ Denote by $\tilde{\pi}_{t}\left(q_{t}, n\right)$ the individual collusive profit in period $t$ when each firm produces $\tilde{q}_{t}$, and by $\pi_{t}^{d}\left(q_{t}, n\right)$ the largest one-shot profit that a firm can make in period $t$ when $\tilde{q}_{t}$ is supposed to be produced by each firm. Some algebra shows that: ${ }^{24}$

$$
\begin{aligned}
& \tilde{\pi}_{t}\left(q_{t}, n\right)=\left(1-n q_{t}\right) q_{t} \mu^{t}, \\
& \pi_{t}^{d}\left(q_{t}, n\right)=\left(\frac{1-(n-1) q_{t}}{2}\right)^{2} \mu^{t} .
\end{aligned}
$$

Now, take any period of time $t \in\{0,1,2, \ldots\}$. Then, at period $t$, perfect collusion can be supported as a MCTSEE by the $n$ firms in the market if and only if the following incentive compatibility constraint (henceforth, ICC) holds: ${ }^{25}$

$\sum_{i=t}^{\infty} \frac{\pi_{i}^{m}}{n} \delta^{i-t} \geq \pi_{t}^{d}\left(\frac{1}{2 n}, n\right)+\sum_{i=t+1}^{\infty} \pi_{i}^{c}(n) \delta^{i-t}$,

which, making use of equations (1), (2), and (4), can be rewritten as follows:

$\frac{\mu^{t}}{4 n} \frac{1}{1-\mu \delta} \geq\left(\frac{n+1}{4 n}\right)^{2} \mu^{t}+\frac{1}{(n+1)^{2}} \frac{\delta \mu^{t+1}}{1-\mu \delta}$,

which in turn implies that the adjusted discount factor $\mu \delta$ must be sufficiently high

$\mu \delta \geq \frac{(n+1)^{2}}{6 n+n^{2}+1} \equiv \widetilde{\mu \delta}(n)$.

Now, two notes are in order. First, the previous condition clearly shows that, for a given number of firms $n$, perfect collusion will be easier

23. As shown in Appendix A, the Cournot individual output in period $t$ when there are $n$ firms in the market is given by $q_{t}^{c}(n)=\mu^{t} /(n+1)$. This implies that $\tilde{q}_{t}$ has to be greater or equal than the perfect collusion individual output rate $\mu^{t} /(2 n)$, but at the same time lower than $q_{t}^{c}(n)$.

24. See Appendix A for details.

25. When $n$ firms perfectly collude in period $t$, then $q_{t}=1 /(2 n)$. 
to sustain as a MCTSEE as $\mu$ increases. ${ }^{26}$ The intuition is simple. Because the number of market participants cannot be affected by market growth, the more the market is growing the higher is the importance of future profits from collusion relative to the current gain from deviating. This is the so called intrinsic pro-collusive effect of demand growth. Second, from (7), it can be easily shown that:

$\frac{d[\widetilde{\mu \delta}(n)]}{d n}=\frac{4\left(n^{2}-1\right)}{\left(6 n+n^{2}+1\right)^{2}}>0$.

The conventional wisdom behind this result is that, ceteris paribus, as the number of firms in the market increases, it becomes more difficult to sustain perfect collusion as a MCTSEE. This implies that, if entry sunk costs turn out not to be prohibitive and there is a potential entrant, the number of firms increases (at least potentially) and this leads to the fact that collusion may be less likely. ${ }^{27}$

In what follows, we analyze the case in which the entry sunk costs are not prohibitive and, therefore, demand growth may stimulate new entry. We start by analyzing firms' optimal behavior after entry and derive the optimal entry date. We then turn to the analysis of the preentry behavior. In particular, we will study the relationship between the maximal level of pre-entry collusion and the parameter $\mu$ measuring market growth.

\section{Sustaining Collusion Ex Post Entry}

The next proposition identifies and characterizes the maximal level of collusion (consistent with equilibrium which may be something less than perfect collusion) that can be sustained after entry. In particular, it shows that if perfect collusion cannot be sustained after entry, then this maximal level of (nonperfect) collusion sustainable after entry increases in the market growth rate.

Proposition 1: Suppose entry occurs at time $t^{\prime}$. Then, the best collusive individual quantity that can be sustained in period $t \geq t^{\prime}$ as a MCTSEE is given by $q^{*}(\mu, \delta) \mu^{t}$, where

26. Put another way, perfect collusion is easier to sustain as a MCTSEE if the market is growing (which means $\mu>1$ ) than if the market were shrinking (which would mean $\mu<1)$.

27. As pointed out by Motta (2004, p. 143), "Suppose ... that both the entrant and the incumbent firms follow an accommodating strategy, with the entrant taking part in the (explicit or tacit) collusive behaviour. Because the larger the number of firms the less likely that collusion can be sustained, entry might break the collusive outcome. All the more so because if a new firm does enter and takes its share of the industry collusive profits, more entrants will be induced to follow the same strategy, and sooner or later collusion will be unsustainable." 
$q^{*}(\mu, \delta)=\left\{\begin{array}{cl}\frac{4-3 \mu \delta}{16-4 \mu \delta}, & \text { if } \mu \delta<4 / 7 \\ \frac{1}{6}, & \text { if } \mu \delta \geq 4 / 7\end{array}\right.$.

Moreover, if $\mu \delta<4 / 7$, then $q^{*}(\mu, \delta)$ decreases with $\mu$.

Proof. For any $t \geq t^{\prime}, n=3$. So, collusion will be sustainable as a MCTSEE if and only if, for any $t \in\left\{t^{\prime}, t^{\prime}+1, t^{\prime}+2, \ldots\right\}$, the following ICC holds

$\sum_{i=t}^{\infty} \delta^{i-t} \tilde{\pi}_{i}\left(q_{t}, 3\right) \geq \pi_{t}^{d}\left(q_{t}, 3\right)+\sum_{i=t+1}^{\infty} \delta^{i-t} \pi_{i}^{c}(3)$.

Making use of equations (1), (3), and (4), the previous ICC can be rewritten as

$\left(1-3 q_{t}\right) q_{t} \sum_{i=t}^{\infty} \delta^{i-t} \mu^{i} \geq\left(\frac{1-2 q_{t}}{2}\right)^{2} \mu^{t}+\frac{1}{16} \sum_{i=t+1}^{\infty} \delta^{i-t} \mu^{i}$,

or, equivalently,

$\left(1-3 q_{t}\right) q_{t} \frac{\mu^{t}}{1-\mu \delta} \geq\left(\frac{1-2 q_{t}}{2}\right)^{2} \mu^{t}+\frac{1}{16} \frac{\delta \mu^{t+1}}{1-\mu \delta}$.

Now, multiplying both sides of the previous condition by $(1-$ $\mu \delta) / \mu^{t}$, the problem becomes stationary (because the $\mu^{t}$ terms cancel out in the previous ICC, each period looks like the first one) and the previous condition is equivalent to

$\left(1-3 q_{t}\right) q_{t} \geq\left(\frac{1-2 q_{t}}{2}\right)^{2}(1-\mu \delta)+\frac{\delta \mu}{16}$.

Hence, given $\delta>0$ and $\mu>1$, period $t^{\prime}$ s best individual collusive output is equal to $q^{*}(\mu, \delta) \mu^{t}$, where $q^{*}(\mu, \delta)$ is the level of $q_{t}$ for which the previous ICC is binding. Some algebra shows that: ${ }^{28}$

$q^{*}(\mu, \delta)=\left\{\begin{array}{cl}\frac{4-3 \mu \delta}{16-4 \mu \delta}, & \text { if } \mu \delta<4 / 7 \\ \frac{1}{6}, & \text { if } \mu \delta \geq 4 / 7\end{array}\right.$.

In addition, if $\mu \delta<4 / 7$, very simple algebra shows that

28. When the ICC (13) is satisfied with equality, it is a quadratic equation in $q_{t}$ and has more than one solution. We are only interested, however, in the smallest (most collusive) solution that falls in the range $q_{t} \in[1 /(2 n), 1 /(n+1))$. More specifically, after entry $n=3$ and, thus, the relevant range is $q_{t} \in[1 / 6,1 / 4)$. 
$\frac{\partial q^{*}(\mu, \delta)}{\partial \mu}=-\frac{2 \delta}{(4-\mu \delta)^{2}}<0$.

This completes the proof.

Corollary 1: Perfect collusion can be sustained ex post entry as a MCTSEE if and only if

$\mu \delta \geq \frac{4}{7}$.

Proof. Because in a perfect collusion scenario the individual output rate in period $t$ equals $\mu^{t} / 6$ (when there are three firms in the market), then the critical discount factor for perfect collusion to be sustainable ex post entry as a MCTSEE follows directly from (9). ${ }^{29}$

Notice now that from (9), one has that, for a given period $t$ following entry, the individual profit of each firm in the market will be equal to $\widetilde{\pi}_{t}(1 / 6,3)$ if $\mu \delta \geq 4 / 7$ and $\widetilde{\pi}_{t}((4-3 \mu \delta) /(16-4 \mu \delta), 3)$ otherwise. Summarizing, individual ex post entry profits are given by $\pi_{t}^{e}=\Pi \mu^{t}$, where

$\Pi=\left\{\begin{array}{cl}\frac{(5 \mu \delta+4)(4-3 \mu \delta)}{16(4-\mu \delta)^{2}}, & \text { if } \mu \delta<4 / 7 \\ \frac{1}{12}, & \text { if } \mu \delta \geq 4 / 7\end{array}\right.$.

Armed with the above expression for ex post entry individual profits, it is now possible to look at the entrants' optimal behavior. The next proposition derives the optimal entry time along the collusive equilibrium path. ${ }^{30}$

Proposition 2: Let

$t_{1}(\mu, \delta, K, \Pi)=\frac{1}{\ln \mu} \ln \left(\frac{\ln \delta}{\ln \delta \mu} \frac{K(1-\delta \mu)}{\Pi}\right)$,

where $\Pi$ is given by equation (17) and $t_{1}(\mu, \delta, K, \Pi)$ decreases in $\mu$. When collusion is supported by MCTSEE, then the optimal entry time is given by $\widehat{t_{1}} \in\left\{\left\lfloor t_{1}\right\rfloor,\left\lceil t_{1}\right\rceil\right\}$, where

$\left\lfloor t_{1}\right\rfloor=\max \left\{t \in \mathbb{N}: t \leq t_{1}(\mu, \delta, K, \Pi)\right\}$

$\left\lceil t_{1}\right\rceil=\min \left\{t \in \mathbb{N}: t \geq t_{1}(\mu, \delta, K, \Pi)\right\}$.

29. The same conclusion could also be obtained from equation $(7), \widetilde{\mu \delta}(3)=4 / 7$.

30. As shown in Appendix B, the optimal entry time is not necessarily the first time period at which the Net Present Value (NPV) of the entrant's profits is non negative. 
Proof. Let us start by regarding $t$ as a continuous variable. Moreover, let $V^{c}(t)$ denote present discounted value of the entrant's profits along the collusive path when it enters in period $t$ and expects to be accommodated in a more inclusive agreement. Then,

$$
V^{c}(t)=\delta^{t} \sum_{i=t}^{\infty} \delta^{i-t} \mu^{i} \Pi-\delta^{t} K=\frac{\delta^{t} \mu^{t} \Pi}{1-\mu \delta}-\delta^{t} K,
$$

where $\Pi$ is given by equation (17). If $t$ is regarded as being a continuous variable, the optimal entry time period is found by solving the following optimization problem:

$\max _{t \geq 1} V^{c}(t)$.

The first-order condition (FOC) of this maximization problem implies that, at the optimal (continuous) entry time, the following holds

$\mu^{t}=\frac{\ln \delta}{\ln (\delta \mu)} \frac{K(1-\mu \delta)}{\Pi}$,

which in turn implies that

$t_{1}(\mu, \delta, K, \Pi)=\frac{1}{\ln \mu} \ln \left(\frac{\ln \delta}{\ln (\delta \mu)} \frac{K(1-\delta \mu)}{\Pi}\right)$.

Notice that in order for $t_{1}(\mu, \delta, K, \Pi) \geq 1$, one must have that

$K \geq \frac{\mu \Pi \ln \delta \mu}{(\ln \delta)(1-\delta \mu)} \equiv \underline{K}$.

Making use of (24), one can now carry out a comparative statics exercise to evaluate how $t_{1}(\mu, \delta, K, \Pi)$ is affected by demand growth:

$\frac{d t_{1}}{d \mu}(\mu, \delta, K, \Pi)=\frac{\partial t_{1}}{\partial \mu}+\frac{\partial t_{1}}{\partial \Pi} \frac{\partial \Pi}{\partial \mu}$,

where some algebra shows that

$\frac{\partial t_{1}}{\partial \mu}$
$=-\frac{\left(\ln \left((\ln \delta) K \frac{1-\delta \mu}{\Pi \ln (\delta \mu)}\right) \ln \delta \mu\right)(1-\delta \mu)+(1-\delta \mu(1-\ln (\delta \mu))) \ln \mu}{\ln (\delta \mu)(\ln \mu)^{2} \mu(1-\delta \mu)}$,

which turns out to be negative for all $K \geq \underline{K}$ (see equation (25)). In addition, 
$\frac{\partial t_{1}}{\partial \Pi}=-\frac{1}{(\ln \mu) \Pi}<0$,

and, from equation (17), one has that

$\frac{\partial \Pi}{\partial \mu}=\left\{\begin{array}{cl}\delta \frac{(4-7 \mu \delta)}{(4-\mu \delta)^{3}}>0, & \text { if } \mu \delta<4 / 7 \\ 0, & \text { if } \mu \delta \geq 4 / 7\end{array}\right.$.

So, from (27)-(29), it can be easily concluded that $d t_{1}(\mu, \delta, K, \Pi) / d \mu$ is negative.

Now, in order to conclude the proof, one has to take into account that, in general, $t_{1}(\mu, \delta, K, \Pi)$ will not happen to be an integer. This being the case, the optimal discrete entry time chosen by the entrant is given by $\widehat{t_{1}} \in\left\{\left\lfloor t_{1}\right\rfloor,\left\lceil t_{1}\right\rceil\right\}$, where

$$
\begin{aligned}
& \left\lfloor t_{1}\right\rfloor=\max \left\{t \in \mathbb{N}: t \leq t_{1}(\mu, \delta, K, \Pi)\right\}, \\
& \left\lceil t_{1}\right\rceil=\min \left\{t \in \mathbb{N}: t \geq t_{1}(\mu, \delta, K, \Pi)\right\} .
\end{aligned}
$$

In particular, $\widehat{t_{1}}=\left\lfloor t_{1}\right\rfloor$ if $V^{c}\left(\left\lfloor t_{1}\right\rfloor\right)>V^{c}\left(\left\lceil t_{1}\right\rceil\right)$. Otherwise, $\widehat{t_{1}}=\left\lceil t_{1}\right\rceil$.

If $t$ was regarded as a continuous variable, then $t_{1}(\mu, \delta, K, \Pi)$ would be the optimal entry time along the collusive path. It is important to note, however, that the model of collusion is based on discrete time and, thus, the optimal entry time must be restricted to be an integer. So, in order to identify the optimal entry date, the entrant compares the (integer) entry dates on either side of $t_{1}(\mu, \delta, K, \Pi)$ and optimally chooses the one for which its present discounted value of profits is highest.

It should be noted as well that a growing market $(\mu>1)$ is essential for entry to take place along the collusive path. The previous proposition assumes that $K \geq \underline{K}$, where $\underline{K}$ is defined by equation (25), in order to make $t_{1}(\mu, \delta, K, \Pi) \geq 1$. If the market were stationary, that is, if $\mu=1$, then, from equation (25), $\underline{K}=\Pi /(1-\delta)$, which in turn implies that the present discounted value of the entrant's profits when it enters in period $t \geq 1$ and expects to be accommodated in a more inclusive agreement would be equal to zero, $V^{c}(t)=0$ for any $t \geq 1$ (see equation (21)). Hence, a necessary (but not sufficient) condition for entry to occur along the collusive path is that $\mu>1 .{ }^{31}$

31. If there is no growth $(\mu=1)$, then either the entrant enters in period $t=0$ (if collusion can be sustained by three firms ex post entry and the entry cost $K$ can be covered by the present discounted value of the entrant's profits when it is accommodated in a more inclusive agreement) or it never enters. 


\section{Sustaining Collusion Pre-Entry}

In this section, we study how the market growth affects the maximal level of collusion that can be sustained pre-entry as a MCTSEE. In order to address this issue, however, we need to determine first the optimal entry time off the equilibrium path, that is, the optimal entry time in case firms play as Cournot oligopolists in every period that follows entry. This is done in the following lemma.

LEMMA 1: Let

$t_{2}(\mu, \delta, K)=\frac{1}{\ln \mu} \ln \left(16 K(1-\delta \mu) \frac{\ln \delta}{\ln \delta \mu}\right)$,

where $t_{2}(\mu, \delta, K)$ decreases in $\mu$. If firms play as Cournot oligopolists in every stage game that follows entry, then the optimal entry time is given by $\widehat{t_{2}} \in$ $\left\{\left\lfloor t_{2}\right\rfloor,\left\lceil t_{2}\right\rceil\right\}$, where

$\left\lfloor t_{2}\right\rfloor=\max \left\{t \in \mathbb{N}: t \leq t_{2}(\mu, \delta, K)\right\}$

$\left\lceil t_{2}\right\rceil=\min \left\{t \in \mathbb{N}: t \geq t_{2}(\mu, \delta, K)\right\}$.

Proof. Let us start by regarding $t$ as a continuous variable. In addition, let $V^{p}(t)$ denote the present discounted value of the entrant's profits when it enters in period $t$ and expects that entry will be followed by Cournot competition in every stage game:

$V^{p}(t)=\delta^{t} \sum_{i=t}^{\infty} \delta^{i-t} \pi_{i}^{c}(3)-\delta^{t} K=\frac{\delta^{t} \mu^{t}}{16(1-\mu \delta)}-\delta^{t} K$,

where the second equality makes use of equation (1).

When $t$ is regarded as a continuous variable, then the optimal entry time off the equilibrium path is found by solving the following optimization problem:

$\max _{t \geq 1} V^{p}(t)$.

From the FOC of this maximization problem, some algebra shows that the optimal entry time is given by

$t_{2}(\mu, \delta, K)=\frac{1}{\ln \mu} \ln \left(16 K(1-\delta \mu) \frac{\ln \delta}{\ln \delta \mu}\right)$,

where we assume that

$K \geq \frac{1}{16} \frac{\mu \ln \mu \delta}{(\ln \delta)(1-\mu \delta)} \equiv \tilde{K}$

in order for $t_{2}(\mu, \delta, K) \geq 1$. 
Now, from (37), a simple comparative statics exercise shows that

$$
\begin{aligned}
& \frac{\partial t_{2}}{\partial \mu} \\
& =-\frac{\left(\ln \left((\ln \delta) 16 K \frac{1-\delta \mu}{\ln (\delta \mu)}\right) \ln \delta \mu\right)(1-\delta \mu)+(1-\delta \mu(1-\ln (\delta \mu))) \ln \mu}{\ln (\delta \mu)(\ln \mu)^{2} \mu(1-\delta \mu)},
\end{aligned}
$$

which turns out to be negative for all $K \geq \tilde{K}$.

Now, in general, $t_{2}(\mu, \delta, K)$ will not happen to be an integer. So, the optimal discrete entry time chosen by the entrant is given by $\widehat{t_{2}} \in$ $\left\{\left\lfloor t_{2}\right\rfloor,\left\lceil t_{2}\right\rceil\right\}$, where

$$
\begin{aligned}
& \left\lfloor t_{2}\right\rfloor=\max \left\{t \in \mathbb{N}: t \leq t_{2}(\mu, \delta, K)\right\}, \\
& \left\lceil t_{2}\right\rceil=\min \left\{t \in \mathbb{N}: t \geq t_{2}(\mu, \delta, K)\right\} .
\end{aligned}
$$

In particular, $\widehat{t_{2}}=\left\lfloor t_{2}\right\rfloor$ if $V^{p}\left(\left\lfloor t_{2}\right\rfloor\right)>V^{p}\left(\left\lceil t_{2}\right\rceil\right)$. Otherwise, $\widehat{t_{2}}=\left\lceil t_{2}\right\rceil$.

So, similar to what happens along the collusive path (see Proposition 2), the entrant will compare the integer entry dates on either side of $t_{2}(\mu, \delta, K)$ (the optimal entry time off the equilibrium path if $t$ is regarded as a continuous variable) and chooses the one for which the present discounted value of its expected profits is highest.

Two more notes regarding this result are worth remarking. First, and similarly to what was mentioned with respect to the result in Proposition 2, a growing market is essential in order for entry to occur off the equilibrium path. Lemma 1 assumes that $K \geq \tilde{K}$, where $\tilde{K}$ is given by equation (38), in order to make $t_{2}(\mu, \delta, K) \geq 1$. If the market were stationary, that is, if $\mu=1$, then, from equation (38), $\tilde{K}=1 /[16(1-\delta)]$, which in turn implies that the present discounted value of the entrant's profits when it enters in period $t \geq 1$ (and expects that entry will be followed by Cournot competition in every period that follows entry) would be equal to zero, $V^{p}(t)=0$ for any $t \geq 1$ (see equation (35)). Hence, a necessary condition for entry to take place along the punishment path is that $\mu>1$. Second, as the market grows faster, entry off the equilibrium path should optimally take place earlier, provided that the entry cost $K$ remains above $\tilde{K}$ (which itself is increasing in $\mu$ ). ${ }^{32}$ This result has the following implication. Take a time period in which entry has

32. Making use of equation (38), some algebra shows that $\partial \tilde{K} / \partial \mu=(\ln \mu \delta+1-$ $\mu \delta) /\left(16(\ln \delta)(1-\mu \delta)^{2}\right)$, which turns out to be positive for any pair $(\delta, \mu)$ such that $\mu>1, \delta \in(0,1)$ and $\mu \delta<1$. 
not occurred yet and suppose that one of the incumbent firms deviates from the collusive agreement. Then, firms will enter into a punishment composed of two distinct phases: a first phase where the incumbents play as Cournot duopolists and a second one in which the incumbents and the entrant form a Cournot triopoly. Now, because $t_{2}(\mu, \delta, K)$ decreases in $\mu$, when the market grows faster, we will have a shorter first phase of the punishment in which firms earn the Cournot duopoly profits in each period and a longer second phase of the punishment in which firms earn the Cournot triopoly profits in each period. In other words, an increase in the market growth rate induces a decrease in the punishment continuation value. As entry occurs sooner along the punishment path, the punishment becomes harsher, which contributes to an increase in the maximal level of pre-entry sustainable collusion.

Let us now turn to the analysis of the conditions for pre-entry incentive compatibility. Assume that $\mu \delta \geq 4 / 7$ so that in the time periods following entry the incumbent firms and the entrant will be able to achieve perfect collusion using grim trigger strategies to punish deviations (Corollary 1 ). Consider now a period $t \in\left\{0,1, \ldots, \widehat{t_{1}}-1\right\}$. Then, collusion can be sustained in period $t$ as a MCTSEE if the following ICC holds:

$$
\begin{aligned}
& \sum_{i=t}^{\widehat{1}_{1}-1} \delta^{i-t} \widetilde{\pi}_{i}\left(q_{t}, 2\right)+\sum_{i=\widehat{t}_{1}}^{\infty} \delta^{i-t} \widetilde{\pi}_{i}\left(\frac{1}{6}, 3\right) \geq \pi_{t}^{d}\left(q_{t}, 2\right)+\sum_{i=t+1}^{t+\widehat{t}_{2}-1} \delta^{i-t} \pi_{i}^{c}(2) \\
& \quad+\sum_{i=t+\widehat{t}_{2}}^{\infty} \delta^{i-t} \pi_{i}^{c}(3),
\end{aligned}
$$

where $q_{t} \in[1 / 4,1 / 3)$ and the collusive quantity that each incumbent firm is supposed to produce in period $t$ equals $\tilde{q}_{t} \equiv q_{t} \mu^{t}$ (see Appendix A for the derivation of profits). In addition, $\widehat{t_{1}}$ and $\widehat{t_{2}}$ are, respectively, given by Proposition 2 and Lemma 1 .

The left hand side of condition (42) represents the present value (from the perspective of period $t$ money) of the collusive profits that an incumbent firm earns along the collusive path when each incumbent firm is producing $\tilde{q}_{t}=q_{t} \mu^{t}$ in period $t<\widehat{t_{1}}$ and $q^{*}(\mu, \delta)=1 / 6$ from period $\widehat{t_{1}}$ onwards. ${ }^{33}$ Notice that from period $t$ to period $\widehat{t_{1}}-1$ there are the two incumbent firms in the industry, while from period $\widehat{t_{1}}$ onwards we have also the entrant as an active firm in the industry (see Proposition 2). The right hand side of condition (42) considers instead what happens if a firm deviates in period $t$. As already mentioned,

33. Remember that from Proposition 1 (equation (9)), one has that for $\mu \delta \geq 4 / 7$, the best collusive (normalized) quantity that can be sustained by the incumbent firms and the entrant as a MCTSEE in the periods following entry is $q^{*}(\mu, \delta)=1 / 6$. 
this deviation will trigger a two-phase punishment. First, from period $t+1$ until period $t+\widehat{t_{2}}-1$, the deviating firm gets the Cournot duopoly profits. Then, from period $t+\widehat{t_{2}}$ onwards, the deviating firm earns the Cournot triopoly profits (see Lemma 1).

Now, making use of equations (1), (3), and (4), the ICC (42) can be rewritten as

$$
\begin{aligned}
& \left(1-2 q_{t}\right) q_{t} \sum_{i=t}^{\widehat{t_{1}}-1}\left(\mu^{i} \delta^{i-t}\right)+\frac{1}{12} \sum_{i=\widehat{t}_{1}}^{\infty}\left(\mu^{i} \delta^{i-t}\right) \\
& \geq\left(\frac{1-q_{t}}{2}\right)^{2} \mu^{t}+\frac{1}{9} \sum_{i=t+1}^{t+\widehat{\tau}_{2}-1}\left(\mu^{i} \delta^{i-t}\right)+\frac{1}{16} \sum_{i=t+\widehat{T}_{2}}^{\infty}\left(\mu^{i} \delta^{i-t}\right),
\end{aligned}
$$

or, equivalently,

$$
\begin{aligned}
(1 & \left.-2 q_{t}\right) q_{t} \frac{(\mu \delta)^{t}-(\mu \delta)^{\widehat{t_{1}}}}{\delta^{t}(1-\mu \delta)}+\frac{1}{12} \frac{\mu^{\widehat{1_{1}}} \delta^{\widehat{1_{1}}-t}}{1-\mu \delta} \geq\left(\frac{1-q_{t}}{2}\right)^{2} \mu^{t} \\
+ & \frac{1}{9} \frac{(\mu \delta)^{t+1}-(\mu \delta)^{t+\widehat{t_{2}}}}{\delta^{t}(1-\mu \delta)}+\frac{1}{16} \frac{\mu^{t+\widehat{t_{2}}} \delta^{\widehat{t_{2}}}}{1-\mu \delta} .
\end{aligned}
$$

The previous ICC implicitly defines a set of feasible values of $q_{t} \in$ $[1 / 4,1 / 3)$ that can be sustained in period $t$ as a MCTSEE.

Even though the ex post entry problem is clearly not stationary, in the following lemma it is shown that considering the ICC in the time period just before entry is sufficient for pre-entry incentive compatibility. In other words, collusion possibilities decrease as the (optimal) entry date approaches.

LemMA 2: To satisfy the incentive compatibility constraint in period $\widehat{t_{1}}-1$, where $\widehat{t}_{1}$ is defined in Proposition 2, is a sufficient condition to ensure pre-entry incentive compatibility.

Proof. See Appendix C.

The intuition behind this result is as follows. The incumbent firms' incentives to deviate increase as they approach the end of the most attractive (first) phase of the collusive path. In particular, in the time period just before the optimal entry date pre-entry (incumbent) firms face a short period of higher profits before entry will occur. The firms therefore face a greater incentive to deviate during this period because future profits become less important relative to the current one-period gain from deviating. The immediate demand growth facing each firm is negative at this point. 
The two following propositions identify sufficient conditions in order for two types of pre-entry equilibria to arise.

Proposition 3: Let $K>\mu^{2} \tilde{K}$, where $\tilde{K}$ is given by equation (38). Then, for any $\mu>1$, there exists a $\tilde{\delta} \in(0,1)$ such that if $4 / 7 \leq \mu \delta \leq \mu \tilde{\delta}$, then no collusion can be sustained as a MCTSEE in any period before entry takes place.

Proof. See Appendix C.

Hence, combining this result with Corollary 1 , one concludes that even when perfect collusion can be sustained (by three firms) after entry takes place, ${ }^{34}$ it may be the case that no collusion can be sustained as a MCTSEE before entry by the two incumbent firms. The intuition is as follows. Take the period of time immediately before entry occurs along the collusive path, period $\widehat{t_{1}}-1$, and notice that $\pi_{t}^{c}(2) / \mu^{t}=1 / 9>$ $\pi_{t}^{c}(1) /\left(3 \mu^{t}\right)=1 / 12>\pi_{t}^{c}(3) / \mu^{t}=1 / 16$. So, an incumbent firm considering whether to collude or not in period $\widehat{t_{1}}-1$ anticipates that if it decides to abide by the collusive agreement, then from period $\widehat{t_{1}}$ onwards it will earn a per-period normalized collusive profit of $1 / 12$. However, if it deviates in the current period, not only it will earn the respective deviation profit, but it will also delay entry, which will occur in $\widehat{t_{2}}$ periods of time (rather than next period). Moreover, the first phase of the punishment is like an extension of the deviation phase because, as indicated above, the (normalized) Cournot duopoly profits each firm earns in the subsequent $\widehat{t_{2}}-1$ periods $(1 / 9)$ exceed the (normalized) perfect collusion profits when there are three firms in the industry $(1 / 12)$. Only in the second phase of the punishment the per-period normalized Cournot profits $(1 / 16)$ will be smaller than the perfect collusion ones. ${ }^{35}$ Now, when the discount factor is sufficiently low (and, thus, the adjusted discount factor $\mu \delta$ is also low), firms attach relatively low weight to future profits and do not resist the temptation to deviate in period $\widehat{t}_{1}-1$. When this is the case, then, by backward induction, one concludes that no collusion can be enforced in any other pre-entry period.

This result is important from an antitrust policy standpoint. By showing that coping with a potential entrant in a market which is

34. Corollary 1 ensures that collusion can be sustained after entry as a MCTSEE whenever $\mu \delta \geq 4 / 7$.

35. Notice that even though defections and punishments at the early duopoly stage delay entry, they are not costly in terms of consumers' welfare when compared to a collusion scenario. It is true that collusion speeds up entry, but, in this model, the entrant is assumed to be accommodated in a more inclusive (perfect collusion) agreement. If entry occurs along the collusive path, the market price stays at the monopoly level, which is independent of the number of firms in the agreement. If instead a deviation occurs and a subsequent (two-phase) Cournot punishment is triggered, the equilibrium market price will be lower than the monopoly price both at the deviation period and during the punishment (i.e., consumers' surplus is enhanced). 
growing over time may completely undermine pre-entry collusive plans of the incumbent firms, it provides a potential explanation for the views of the EC and the CFI that higher demand growth is a factor that makes collusion less of a concern.

Proposition 4: For any $\mu>1$, there exists a $\delta^{*} \in(0,1)$ such that if $\mu \delta>$ $\mu \delta^{*} \geq 4 / 7$, perfect collusion can (also) be sustained as a MCTSEE in any period before entry takes place.

Proof. See Appendix C.

So, the sustainability of perfect collusion pre-entry relies on the adjusted discount factor $\mu \delta$ being sufficiently high (and higher than the threshold value above which perfect collusion can be sustained as a MCTSEE after entry, 4/7). Only when the market growth is sufficiently fast the pro-collusive intrinsic effect of demand growth turns out to be sufficiently strong to more than compensate for the impact of entry which is likely to be stimulated by demand growth on pre-entry collusion.

Our results therefore reveal that standard supergame models of collusion may give misleading predictions regarding the effect of demand growth on the extent of collusion which can be sustained by the incumbent firms in the market, because they disregard the fact that market growth may stimulate new entry. The analysis clearly suggests that, as emphasized by Ivaldi et al. (2003), if entry barriers are moderate, then it is very important to disentangle the pro-collusive intrinsic effect of demand growth from the impact of entry which is likely to be stimulated by market growth. By so doing, one can assess the relative strengths of these effects so as to try and understand what is the overall net impact of market growth on the extent of collusion which can be sustained by the firms in the industry.

In what follows, we present a numerical example where the results in the two previous propositions will be at work. Remember that we have restricted attention to the case in which, after entry, the incumbent firms and the entrant will be able to sustain perfect collusion as a MCTSEE. So, the relevant region of parameter values $(4 / 7 \leq \mu \delta<1)$ is represented by all pairs $(\delta, \mu)$ in between the two dashed lines in Figure 1.

Now, assuming that $K=1,{ }^{36}$ the two thick lines in Figure 1 represent the sufficient conditions identified by Propositions 3 and $4 .{ }^{37}$

36. It is important to note that other examples were computed, assuming different values for $K$, and the results were always qualitatively the same as the ones presented here for $K=1$.

37. In particular, curves $\tilde{\delta}(\mu)$ and $\delta^{*}(\mu)$ were constructed making use of equations (C10) and (C15), respectively. 


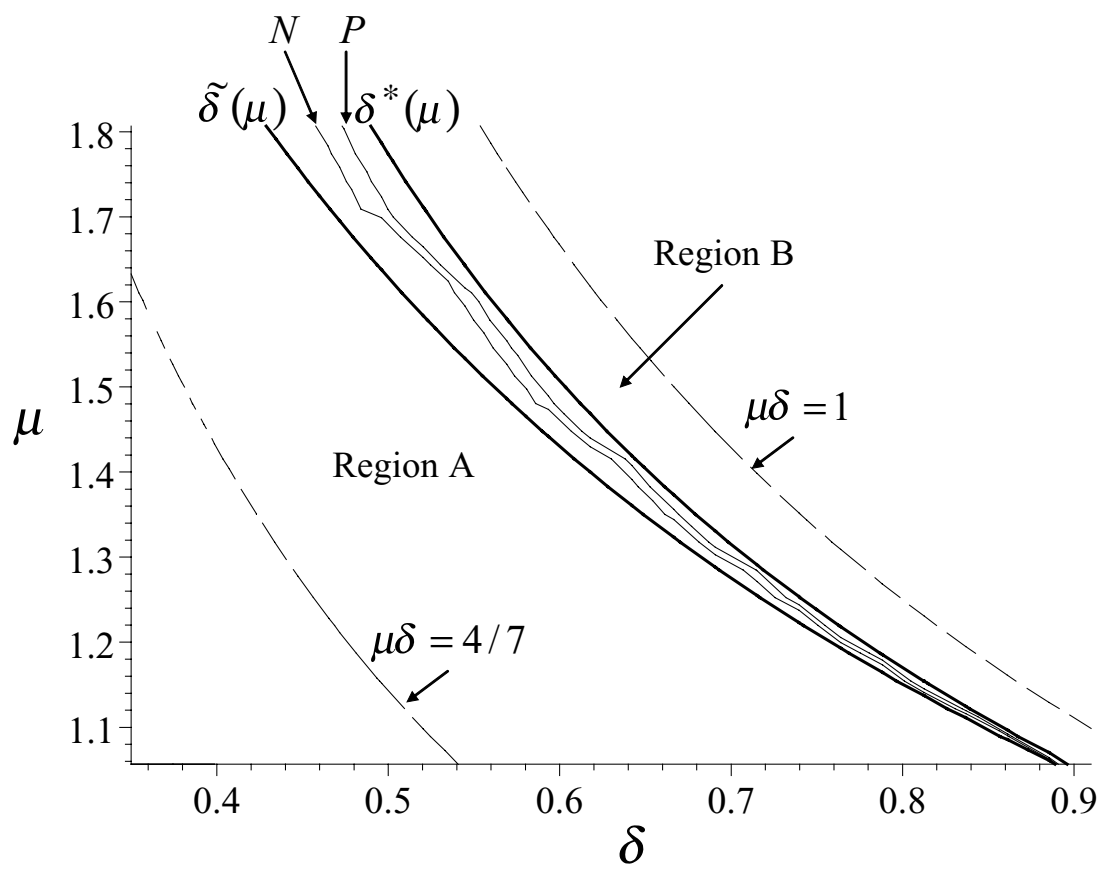

FIGURE 1. NUMERICAL EXAMPLE $(K=1)$

Figure 1 also presents two other curves—curves $N$ and $P$ - which are, for this specific example, the "true" bounds on the adjusted discount factor $\mu \delta$ that can be used to identify the regions of parameter values where the two types of equilibria exist. These two bounds were constructed making use of the ICC in period $\widehat{t_{1}}-1$ and taking into account the discrete nature of the optimal entry times $\widehat{t_{1}}$ and $\widehat{t_{2}}$. In particular, for all pairs $(\delta, \mu)$ in the region between curve $P$ and the dashed line where $\mu \delta=1$, perfect collusion can be sustained before and after entry as a MCTSEE (the sufficient condition identified in Proposition 4 ensures that this type of equilibrium will occur in region $B$ of Figure 1). On the other hand, there is a region of parameter values, composed of all pairs $(\delta, \mu)$ which lie in between the dashed line $\mu \delta=4 / 7$ and curve $N$, where no collusion can be sustained as a MCTSEE before entry (the sufficient condition identified in Proposition 3 guarantees that this type of equilibrium will exist in region $A$ of the above Figure).

Two more notes are worth remarking regarding the example under consideration. First, notice that the region of parameter values not explained by the conditions derived in Propositions 3 and 4 is relatively small. Second, the region where no collusion can be sustained before 
entry (associated with the most relevant equilibrium from a policy standpoint) is substantially larger than the region of parameter values where perfect collusion is sustained both before and after entry.

Before concluding this section, let us discuss two important limitations of the proposed model.

\section{Optimal Penal Codes}

A first limitation of our analysis is that firms employ grim trigger strategies while it is well known that Abreu $(1986,1988)$ has characterized a stronger type of punishment strategies with a stick and carrot structure. This obviously limits the payoffs attainable in the repeated game. ${ }^{38}$ So, a natural question that can be raised is whether the results in the paper regarding the supportability of collusion in the pre-entry duopoly, and in particular the negative result in Proposition 3, hold good when firms use Abreu-style threats.

As explained above, ${ }^{39}$ we restrict attention to this class of simple punishment strategies for tractability reasons. Characterizing optimal penal codes in our setting is a very difficult exercise for several reasons. First, the penal code would consist of nonstationary equilibrium strategies. The strategy profiles would have to take into account that the quantity produced by each firm along the punishment phases would have to be contingent on the level of demand in each period of time following a deviation. ${ }^{40}$ Second, in constructing the optimal punishment, one has also to take into account that demand growth might trigger entry and, therefore, the strategy profiles should also consider the number of firms in the market in each period of time. Lastly, notice that, because prices are bounded below by zero, one would have to assume that, not only firms' marginal costs are positive, ${ }^{41}$ but also that the demand function is piecewise linear (i.e., $p_{t}=\max \left\{0,1-Q_{t} / \mu^{t}\right\}$ ), with no restriction imposed on the maximum industry total output. If instead the quantity space is assumed to be bounded (say, $Q_{t} \in\left[0, \mu^{t}\right]$ ),

38. As noted by Harrignton (1991, p. 390), "[b]y being able to credibly threaten a more harsh retribution for defection, an oligopoly can support a wider set of collusive outcomes."

39. See Footnote 20.

40. In contrast, for the infinitely repeated Cournot output game with stationary demand, Abreu (1986) found that, for the case of symmetric punishments, an optimal punishment strategy takes a very simple form. Not only it has a stick and carrot structure, but it is also "history-independent" in the following sense: it is always the same punishment independent of $(i)$ the period of time in which a deviation occurred; and (ii) the (previous) history of the game.

41. Extending the previous results of the paper to the case in which firms' marginal costs are positive is a trivial exercise which would have no qualitative impact on the results. 
then this would imply a lower bound on the static profit. There would be then no assurance that a most severe punishment strategy equilibrium could have a first phase (of very high quantity and low profit) lasting for a single period.

It should be noted, however, that optimal penal codes are not necessarily "security level" penal codes, that is, an optimal penal code does not always yield each firm a present discounted value of profits after a deviation $\left(V^{P}\right)$ equal to zero (the lowest payoff a deviating firm can be held down to by other firms in the industry). As pointed out by Motta (2004), in order for a firm to abide by a collusive agreement where stick and carrot strategies are implemented, it must be the case that both the ICC along the collusive path and the ICC along the punishment path must hold. Moreover, these two ICCs depend on the harshness of the punishment being inflicted on a deviating firm. The harsher the punishment is, the more likely is that the ICC on the collusive path is satisfied, but, at the same time, a harsher punishment tightens the ICC on the punishment path. So, for the stationary demand case, Motta (2004, p. 171) finds that "the best possible strategies (in the sense that they allow firms to enforce collusion for the largest possible range of discount factors) are not necessarily those which require the strongest possible punishment $V^{P}=0$. The harsher the punishment, the higher the discount factor needed for making the return to collusion desirable enough to participate in the punishment itself. Imposing $V^{P}=0$ might make the IC[C] along the punishment path even tighter than the ICIC] along the collusive path. This is precisely what happens when a small number of firms operate in the industry." As Motta (2004) shows for the linear demand case, when the number of firms in the industry is low, having a "security level" penal code would require a too high discount factor for the punishment to be enforced. As a result, "it is better to resort to a milder punishment under which $V^{P}>0 .{ }^{\prime \prime}$ In other words, the severity of optimal stick and carrot punishments in a Cournot supergame with linear and static demand has been shown to be lower when the number of firms in the industry is low. This characteristic of Abreu-style threats will probably hold as well in a setting where demand is growing over time. This makes us believe that the negative result of our paper (put forward in Proposition 3) will still hold good in situations where there are few firms in the market, which are the most relevant (and most common) ones in merger analysis.

\section{Incumbent's Reaction to Entry}

A second limitation of our analysis is that collusion among incumbents unambiguously facilitates entry. Even though, as explained above, some 
anecdotal evidence suggests that this strategy is usual in growing markets ${ }^{42}$ thinking at the real world, one would think that incumbents could also collude on trying to keep the entrant out. Examples of concerted practices that the incumbents may decide to use so as to try and prevent entry, include: (i) to jointly fighting the entrant with selective price/output wars in the areas/demand segments the entrant is trying to penetrate; (ii) lobbying for legislative restrictions on trade, safety or health issues hurting the potential entrant, especially if this potential entrant is a foreign firm or a firm using a different technology; ${ }^{43}$ (iii) recruiting key employees of the potential entrant; and (iv) boycotting the entrant's potential customers and suppliers. ${ }^{44}$ The adoption of this type of strategies may or may not entail preventing entry by the potential entrant. It will certainly, however, yield a more restrictive set of conditions under which entry is optimal. So, it seems important to test the robustness of our findings to the use of this alternative class of (entry deterrence) strategies by the incumbent firms in the industry. This will be done in our future research. Hopefully, the above model can be seen as a stepping stone in the direction of a more complete analysis.

\section{Extensions}

In this section we discuss two possible extensions of the basic model.

\section{Multiple Entrants}

The assumption that entry can occur only once, while the market continues to grow, is an important limitation of the model. Clearly, in

42. See Section 2.1.

43. Note that, as ponted out by to Harrington (2006, p. 69), "A final tactic to forestall entry ... is for cartel members to coordinate in not sharing the technology required for producing the product. This was apparently done in the graphite electrodes and sorbates cartels."

44. From 1992, the Swedish-Swiss industrial combine ABB participated in a cartel amongst district heating pipe producers across Europe where some of these entry deterrence strategies have been used against Powerpipe, a cartel outsider considering entry into new geographic markets like Germany (Case No IV/35.691 /E-4: Pre-Insulated Pipe Cartel, Official Journal of the European Communities, L 24/1, 30.1.1999). As explained in paragraph 13 of the Decision of the CFI (Fourth Chamber) of 20 March 2002 (Brugg Rohrsysteme GmbH $v$ Commission of the European Communities), a characteristic feature of this cartel was "the adoption and implementation of concerted measures to eliminate Powerpipe, the only major undertaking which was not a member." In particular, "certain members of the cartel recruited key employees of Powerpipe and gave Powerpipe to understand that it should withdraw from the German market. Following the award to Powerpipe of an important German project, a meeting took place in Düsseldorf in March 1995 which was attended by the six major producers and Brugg .... It was decided at that meeting to organise a collective boycott of Powerpipe's customers and suppliers. The boycott was subsequently implemented." 
practice, faster growing markets might have more entry. In our defense, this analysis is offered as a counterpoint to standard modeling wherein the number of market participants is presumed to be unchanged despite the market growth. In addition, it allows us to obtain clear intuitions on the main results.

While a model with more than one entrant has generality on its side, it would also be significantly more difficult to obtain results, especially closed-form solutions for pre-entry equilibria. The main reason is that if there is a pool of $m$ potential entrants, then, when analyzing incentive compatibility in a time period before the first entrant comes into the industry, one will have to consider the existence of $m+1$ different phases along the collusive path and also $m+1$ different phases along the punishment path.

In what follows, let us analyze the case in which there are two potential entrants in the industry $(m=2)$. Consider first firms' optimal behavior after the two entrants have entered the industry. Suppose entry by the second entrant occurred at time $t^{*}$. Then, making use of equation (7), one may conclude that perfect collusion can be sustained after entry by the two potential entrants if and only if the adjusted discount factor is sufficiently high:

$\mu \delta \geq \frac{25}{41} \equiv \widetilde{\mu \delta}(4)$.

Now, the relevant question is: when will the entrants decide to enter the industry? Let $t_{1}^{j}$ and $t_{2}^{j}$ denote entrant $j^{\prime}$ s, $j=1,2$, optimal entry time along the collusive equilibrium path and along the punishment path, respectively. Clearly, both along the collusive equilibrium path and along the punishment path, the first entrant will decide to enter the industry as soon as the NPV of its profits is non negative. ${ }^{45}$ But what about the second entrant, that is, how do we determine $t_{1}^{2}$ and $t_{2}^{2}$ ? Following a reasoning very similar to the proofs of Proposition 2 and Lemma 1, which is omitted here for the sake of brevity, one may conclude that entrant 2 's optimal entry times are given by: ${ }^{46}$

$t_{1}^{2}=\frac{1}{\ln \mu} \ln \left(\frac{\ln \delta}{\ln \mu \delta} \frac{K(1-\mu \delta)}{\Pi_{2}}\right)$,

where $\Pi_{2} \mu^{t}$ represents the second entrant's profits in the post-entry (collusive) period $t$, and

$t_{2}^{2}=\frac{1}{\ln \mu} \ln \left(25 K(1-\mu \delta) \frac{\ln \delta}{\ln \mu \delta}\right)$.

45. Competition between the two potential entrants explains that the first entrant will decide to enter as soon as the NPV of its profits covers the entry sunk cost $K$.

46. To simplify the exposition, in this Section we are ignoring integer constraints. 
Armed with the above expressions for entrant 2's optimal entry times, it is now possible to consider the case of entry into a triopoly. Assume that $\mu \delta \geq 25 / 41$ so that in the time periods following entry by the two potential entrants the four firms in the industry will be able to achieve perfect collusion using trigger strategies to punish deviations. Then, consider the time period just before the second entrant would come in along the collusive path (i.e., consider $t=t_{1}^{2}-1$ ). At this specific time period, perfect collusion can be sustained as a MCTSEE between the three firms in the industry if the following ICC holds: ${ }^{47}$

$$
\begin{aligned}
& \frac{\pi_{t_{1}^{2}-1}^{m}}{3}+\sum_{i=t_{1}^{2}}^{\infty} \frac{\pi_{i}^{m}}{4} \delta^{i} \geq \pi_{t_{1}^{2}-1}^{d}\left(\frac{1}{6}, 3\right)+\sum_{i=t_{1}^{2}}^{t_{1}^{2}+t_{2}^{2}-1} \pi_{i}^{c}(3) \delta^{i-t_{1}^{2}+1} \\
& +\sum_{i=t_{1}^{2}+t_{2}^{2}}^{\infty} \pi_{i}^{c}(4) \delta^{i-t_{1}^{2}+1},
\end{aligned}
$$

where $t_{1}^{2}$ and $t_{2}^{2}$ are, respectively, given by equations (46) and (47). Now, making use of equations (1), (2), and (4), and after some rearranging, condition (48) can be rewritten as

$$
\frac{1}{36} \mu^{t_{1}^{2}-1} \leq \frac{1}{16} \frac{\delta \mu^{t_{1}^{2}}}{1-\mu \delta}-\left(\frac{1}{16} \frac{(\delta \mu)^{t_{1}^{2}}-(\delta \mu)^{t_{1}^{2}+t_{2}^{2}}}{\delta_{1}^{t_{1}^{2}-1}(1-\mu \delta)}+\frac{1}{25} \frac{\delta_{2}^{t_{2}^{2}+1} \mu_{1}^{t_{1}^{2}+t_{2}^{2}}}{1-\mu \delta}\right) .
$$

Now, multiplying both sides of the previous ICC by $\delta^{t_{1}^{2}-1}(1-\mu \delta)$, and after some algebra, one obtains that condition (49) is equivalent to:

$-\frac{(\mu \delta)^{t_{1}^{2}-1}}{3600}\left(-100+100 \mu \delta+81(\mu \delta)^{t_{2}^{2}+1}\right) \leq 0$.

The previous ICC implicitly defines a threshold value for the adjusted discount factor, denoted as $(\mu \delta)$, above which the three firms in the industry can sustain perfect collusion as a MCTSEE in the time period just before the second entrant would come in along the collusive path. Figure 2 presents a numerical example where, assuming that $K=1$, this threshold value for the adjusted discount factor is identified.

Remember that we have restricted attention to the case in which, after entry by the two potential entrants, the four firms in the industry will be able to sustain perfect collusion as a MCTSEE. Hence, the relevant region of parameter values $(25 / 41 \leq \mu \delta<1)$ is represented by all pairs $(\delta, \mu)$ in between the two dashed lines in Figure 2.

47. When the three firms in the industry perfectly collude in period $t_{1}^{2}-1$, then each of them will produce $q_{t_{1}^{2}-1}^{c}(1) / 3=\mu^{t} / 6$. 


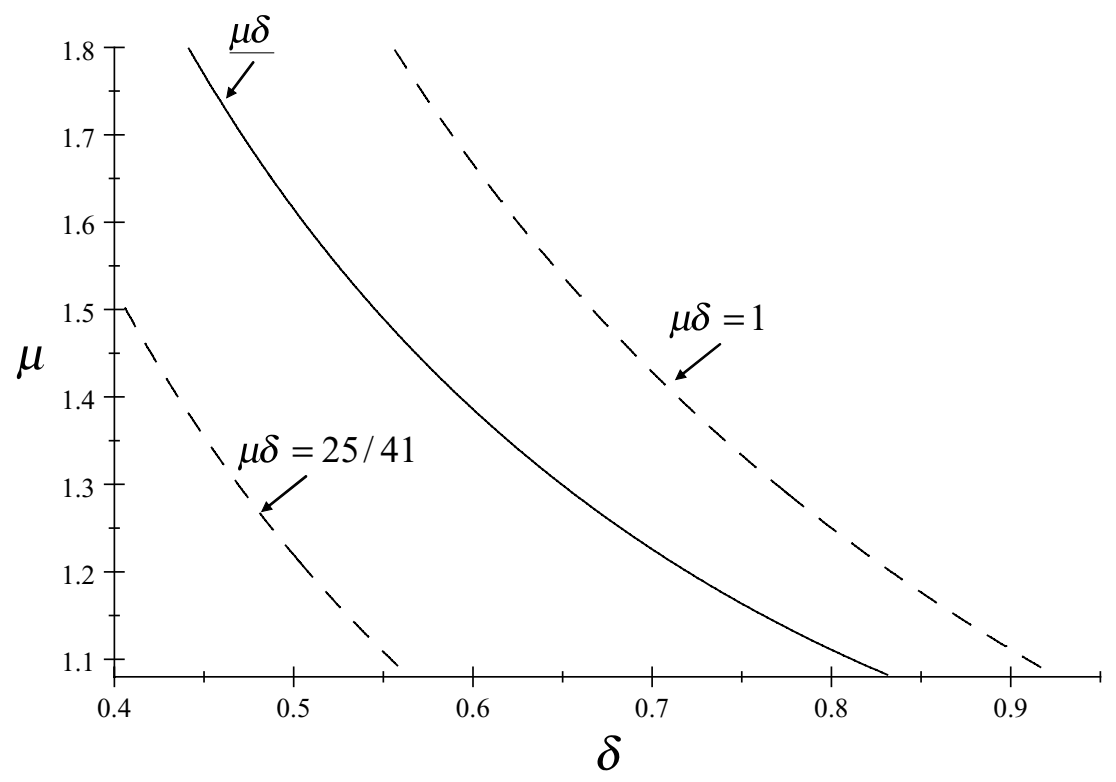

FIGURE 2. ENTRY INTO A TRIOPOLY-NUMERICAL EXAMPLE $(K=1)$

The figure illustrates that, as expected, as long as the adjusted discount factor is sufficiently high, perfect collusion can be sustained both after and before entry by the second entrant. In addition, and perhaps more importantly, it also illustrates that there exists a region of parameter values (namely, the region where $25 / 41 \leq \mu \delta<\mu \delta$ ) in which even though perfect collusion can be sustained (by four firms) after the two entrants have decided to enter the industry, the two incumbents and the first entrant will not be able to perfectly collude before entry by the second entrant. The intuition behind this result is as follows. Notice that $\pi_{t}^{c}(1) /\left(4 \mu^{t}\right)=\pi_{t}^{c}(3) / \mu^{t}=1 / 16>\pi_{t}^{c}(4) / \mu^{t}=1 / 25$. Now, consider the period of time just before the second entrant would come in along the collusive path $\left(t=t_{1}^{2}-1\right)$. At this specific time period, each of the three firms already in the market anticipates that in case it decides to respect the collusive agreement, then from period $t_{1}^{2}$ onwards there will be four firms in the industry earning a per-period normalized collusive profit equal to $1 / 16$. If, however, one of these three firms decides to deviate in the current period, then, not only it will earn the corresponding deviation profits, but it will also delay entry by the second entrant, which will occur in $t_{2}^{2}$ periods of time (rather than next period). Moreover, during the first phase of the punishment (i.e., in the 
$t_{2}^{2}-1$ periods following its deviation), the deviating firm will earn a perperiod Cournot profit equal to $1 / 16$, which exactly coincides with the (normalized) individual perfect collusion profits when there are four firms in the industry. Only in the second phase of the punishment, the per-period (normalized) Cournot profits $(1 / 25)$ will be smaller than the perfect collusion ones. So, by deviating in period $t_{1}^{2}-1$ a firm will induce a delay in the effective punishment of $t_{2}^{2}$ periods of time. This being the case, if the adjusted discount factor is sufficiently low, then the two incumbents and the first entrant will attach low weight to their future profits and will not resist the temptation to deviate from the perfect collusion agreement in period $t_{1}^{2}-1$.

Before concluding this section, let us think about the case in which there are more than two potential entrants. Notice that, also in this case, it is still true that, when firms in the market consider incentive compatibility in the time periods just before the first and the second entrant would come in along the perfect collusion path, a deviation (in those specific time periods) and the following punishment phase may become more attractive than abiding by the (perfect) collusive agreement. Thanks to the additional effect of a deviation (and the subsequent punishment) in terms of delaying the next entry, a firm in the market will always be able to obtain: (i) an extension of the deviation phase in case its deviation occurs just before the first entrant would enter along the perfect collusion path; and (ii) a delay in the effective punishment in case its deviation takes place just before the second entrant would come in along the perfect collusion path. This makes us believe that the main results of the paper would extend to a more complete model with a pool of more than two potential entrants.

\section{Partial Collusion}

So far, we have focused attention on the analysis of full collusion, that is, it has been assumed that all active firms in the market were colluding. An interesting question, however, is to analyze whether partial collusion between the two incumbent firms is feasible in this setting. In particular, suppose now that the two incumbent firms are members of a cartel and should entry occur while the cartel is operating, the entrant becomes a fringe competitor which in every period picks an output that maximizes its own profit. ${ }^{48}$

For every period $t$ in which it is active, the entrant plays a one period best-response to the cartel's aggregate output, that is, selects its output along the following reaction function:

48. The cartel acts as a Stackelberg quantity leader against the Cournot entrant. 
$q_{f, t}=\frac{\mu^{t}-Q_{K, t}}{2}$

where $Q_{K, t}$ denotes the cartel output in period $t$.

From (51), the residual demand facing the cartel in period $t$ is

$p_{t}=\frac{\mu^{t}-Q_{K, t}}{2 \mu^{t}}$.

Profit maximization for the cartel implies that in each period $t$ it will produce the monopoly output:

$Q_{K, t}=\frac{\mu^{t}}{2}$.

Substituting (53) into (51) and (52), one obtains the fringe firm output and the cartel price in each period $t$

$q_{f, t}=\frac{\mu^{t}}{4}$

$p_{t}=\frac{1}{4}$.

Individual profits of cartel firms and the fringe firm are, respectively, given by

$\pi_{K, t}=\frac{\mu^{t}}{16}$

$\pi_{f, t}=\frac{\mu^{t}}{16}$

So, two notes are in order at this point. First, there is no freeriding problem in this setting because $\pi_{K, t}=\pi_{f, t} \cdot{ }^{49}$ Second, and most importantly, notice that $\pi_{K, t}=\pi_{f, t}=\pi_{t}^{c}(3)$. In other words, by partially colluding, cartel members can earn no higher profit than the Cournot individual profit in each period of time. Partial collusion is therefore unfeasible in this setting.

It is important to underline at this point that this result is consistent with the models by Martin (1990) and Shaffer (1995). It is easy to show that in those models as well, it turns out that if two firms form a cartel and act as Stackelberg leader against a Cournot fringe composed of a single firm, then the cartel is not able to earn a (per-period) profit exceeding the Cournot triopoly profit.

49. This result is in line with Shaffer (1995) who shows that in an industry where $n$ firms face a linear demand and linear costs and compete in quantities, a cartel composed of $k<n$ firms and acting as a Stackelberg leader with respect to the fringe does not necessarily face the free-rider problem. In particular, in Proposition 1 of Shaffer (1995) it is shown that if the cartel is sufficiently small $(k \leq(n+1) / 2)$, then each firm in the cartel earns a profit which is no smaller than that of a fringe firm. 


\section{Conclusion}

This paper has explored the relationship between demand growth and collusion in a model where market growth can trigger future entry. This is an issue which has received very little attention in the previous literature on tacit collusion, but is of utmost importance for understanding the relationship between demand growth and firms' market power in an industry.

After entry, when the number of market participants can no longer be affected by market growth, the standard intrinsic pro-collusive effect of demand growth is shown to prevail: the expected rise in demand increases the future cost of deviation, which in turn implies that an increase in the market growth rate induces an increase in the maximal level of sustainable post entry collusion.

It turns out, however, that, even in situations where demand growth is sufficiently strong so that perfect collusion can be sustained after entry, coping with a potential entrant may completely undermine any pre-entry collusive plans of the incumbent firms. This analysis, therefore, clearly suggests that, as emphasized by Ivaldi et al. (2003), when studying the impact of demand growth on (pre-entry) collusion, it is crucial to try and disentangle the pro-collusive intrinsic effect of demand growth from the impact of entry and other factors affected by market growth so as to assess their relative strengths. By so doing, the current paper sheds some light on the understanding of why the EC and the CFI usually interpret demand growth as a factor hindering collusion, an interpretation which contrasts with the conclusion of tacit collusion models with growing demand where the possibility of entry is assumed away.

\section{Appendix A: Profits}

In this section, we derive the per-period profits earned by each firm in three alternative scenarios: Cournot oligopoly, collusion and one-shot deviation from the collusive norm.

\section{A.1 Cournot}

In a Cournot-Nash equilibrium for the single period game played in period $t$ when there are $n$ firms in the industry, a representative firm $i$ chooses its output by solving the following maximization problem.

$$
\max _{q_{i, t}}\left\{\left(1-\frac{\sum_{i=1}^{n} q_{i, t}}{\mu^{t}}\right) q_{i, t}\right\} .
$$


The associated FOC is given by

$1-\frac{1}{\mu^{t}}\left(\sum_{j \neq i}^{n} q_{j, t}+2 q_{i, t}\right)=0$.

By symmetry, $\forall i \in\{1, \ldots, n\}, q_{i, t}=q_{t}$. Hence, the individual output rate in period $t$ is

$q_{t}^{c}(n)=\frac{\mu^{t}}{n+1}$.

Now, the industry equilibrium output and equilibrium profits are, respectively, given by

$Q_{t}^{c}(n)=\frac{n}{n+1} \mu^{t}$,

$\pi_{t}^{c}(n)=\left(\frac{1}{n+1}\right)^{2} \mu^{t}$

\section{A.2 Collusion}

Assume now that in period $t$ there are $n$ firms colluding in the market. Let $\tilde{q}_{t} \equiv q_{t} \mu^{t}$ denote the individual collusive output rate, where $q_{t} \in$ $\left[\frac{1}{2 n}, \frac{1}{n+1}\right)$. Then, it is straightforward to show that the industry output rate and the individual profits in this period $t$ are given by

$\tilde{Q}_{t}=n q_{t} \mu^{t}$

$\tilde{\pi}_{t}\left(q_{t}, n\right)=\tilde{p}_{t} \tilde{q}_{t}=\left(1-n q_{t}\right) q_{t} \mu^{t}$

\section{A.3 Deviation}

If a given firm is considering deviating in period $t$, when each firm is supposed to produce $\tilde{q}_{t} \equiv q_{t} \mu^{t}$, then the deviating firm optimal deviation output will result from the following optimization problem:

$$
\max _{q_{t}^{d}}\left\{\left(1-\frac{(n-1) q_{t} \mu^{t}+q_{t}^{d}}{\mu^{t}}\right) q_{t}^{d}\right\} .
$$

The associated FOC is:

$1-\frac{(n-1) q_{t} \mu^{t}+2 q_{t}^{d}}{\mu^{t}}=0$.

Hence, very simple algebra shows that:

$q_{t}^{d}=\frac{1-(n-1) q_{t}}{2} \mu^{t}$. 
In addition, the industry output rate and the deviator's individual profit are, respectively, given by

$$
\begin{aligned}
& Q_{t}^{d}=\left((n-1) q_{t} \mu^{t}+q_{t}^{d}\right)=\left(\frac{1+(n-1) q_{t}}{2}\right) \mu^{t}, \\
& \pi_{t}^{d}(q, n)=\left(\frac{1-(n-1) q_{t}}{2}\right)^{2} \mu^{t} .
\end{aligned}
$$

\section{Appendix B: Delayed Entry}

In this section, we discuss a side result of the analysis regarding the optimal time of entry. In the analysis above, entry is optimized (see Proposition 2 and Lemma 1). It is interesting to note, however, that the optimal entry time may not coincide with the time period in which the Net Present Value (NPV) of the entrant's expected profits becomes nonnegative. This is shown in the following Lemma:

LemMA 3: Let $\underline{t}$ denote the first period in time at which the NPV of the entrant's expected profits is positive. The entrant will optimally choose to enter in period $\underline{t}+\tau, \tau \in\{1,2, \ldots\}$ rather than in period $\underline{t}$ if the following condition holds

$\left(1-(\mu \delta)^{\tau}\right) K<\Pi \mu^{\underline{t}}\left(1+\mu \delta+\cdots+(\mu \delta)^{\tau-1}\right)<\left(1-\delta^{\tau}\right) K$,

where $\Pi$ is given by (17).

Proof. By definition, $\underline{t}$ is the first period in time at which the NPV of the entrant's expected profits is positive. In addition, the entrant's payoff in each period $t \geq \underline{t}$ is $\pi_{t}^{e}=\Pi \mu^{t}$, where $\Pi$ is given by (17). Hence, the following condition must hold because it just requires that entering in period $\underline{t}$ yields a positive NPV of profits to the entrant:

$\sum_{i=\underline{t}}^{\infty} \delta^{i-\underline{t}} \Pi \mu^{i}=\frac{\Pi \mu^{\underline{t}}}{1-\mu \delta}>K$,

or, equivalently,

$\Pi \mu^{\underline{t}}>(1-\mu \delta) K$.

Now, from the point of view of period $\underline{t}$ money, delaying entry to period $\underline{t}+\tau$ will be preferred to entering in period $\underline{t}$ if

$\delta^{\tau}\left(\sum_{i=\underline{t}+\tau}^{\infty} \delta^{i-\underline{\underline{t}}+\tau)} \Pi \mu^{i}-K\right)>\sum_{i=\underline{t}}^{\infty} \delta^{i-\underline{t}} \Pi \mu^{i}-K$, 
$\frac{\delta^{\tau} \Pi \mu^{\underline{t+\tau}}}{1-\mu \delta}-\delta^{\tau} K>\frac{\Pi \mu^{\underline{t}}}{1-\mu \delta}-K$,

or, equivalently,

$\left(1-\delta^{\tau}\right) K>\frac{\Pi \mu^{\underline{t}}}{1-\mu \delta}\left(1-(\mu \delta)^{\tau}\right)$.

Now, making use of the fact that $1-(\mu \delta)^{\tau}=(1-(\mu \delta))(1+\mu \delta+$ $\left.\cdots+(\mu \delta)^{\tau-1}\right)$, conditions (B3) and (B6) can, respectively, be rewritten as follows

$\left(1+\mu \delta+\cdots+(\mu \delta)^{\tau-1}\right) \Pi \mu^{\underline{t}}>\left(1-(\mu \delta)^{\tau}\right) K$,

$\left(1-\delta^{\tau}\right) K>\Pi \mu^{\underline{t}}\left(1+\mu \delta+\cdots+(\mu \delta)^{\tau-1}\right)$.

Hence, conditions (B2) and (B4) (or, equivalently, (B7) and (B8)) will simultaneously hold if

$\left(1-(\mu \delta)^{\tau}\right) K<\Pi \mu^{\underline{t}}\left(1+\mu \delta+\cdots+(\mu \delta)^{\tau-1}\right)<\left(1-\delta^{\tau}\right) K$.

This completes the proof.

Hence, contrary to what happens in standard supergame models of collusion that examine entry in a context where demand is constant over time, in our setting the optimal entry time may not correspond to the first period in time at which the NPV of the entrant's payoff is non negative. The intuition behind this result is simple. Notice that a profitable entry in period $\underline{t}$ can be based on very low profits in the initial periods (say, periods $\underline{t}, \underline{t}+1, \ldots, \underline{t}+\tau-1)$ and substantially higher profits in future periods (due to a highly increasing demand). By contrast, the entry cost is constant throughout time, which explains why entry can be optimally delayed (to period $\underline{t}+\tau$ ). While the delay costs $\tau$ periods of profits, it also delays the payment of the entry costs for $\tau$ periods. We can then have the latter benefit outweighing the former cost, and entry in period $t$ having a positive NPV of post entry profits, if the condition put forward in the previous Lemma is satisfied.

This result is not central to the analysis and is related to the restriction that there exists a single potential entry in the market. Notice, however, that it will not disappear for any other number of potential entrants. If this number is finite, then competition between potential entrants will imply that every entrant but the last one would enter as soon as its NPV of profits becomes non negative. However, the last entrant will face a trade-off similar to the one described above for the 
single potential entrant case and, therefore, may decide to delay its entry beyond that point.

\section{Appendix C: Proofs}

\section{C.1 Proof of Lemma 2}

Making use of (44) and setting $q_{t}=1 / 4$, some algebra shows that the ICC in period $t=\widehat{t_{1}}-1$ can be written as follows:

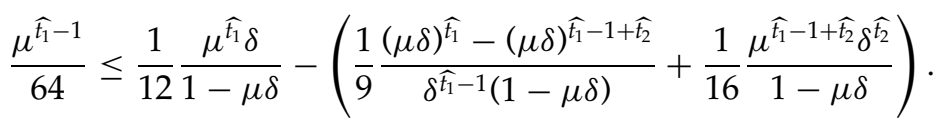

Multiplying both sides by $\delta^{\widehat{\mathrm{t}}_{1}-1}(1-\mu \delta)$, and after some rearranging, the previous ICC becomes:

$$
\frac{(\mu \delta)^{\widehat{T}_{1}-1}}{576}\left(9+7 \mu \delta-28(\mu \delta)^{\widehat{t_{2}}}\right) \leq 0 .
$$

So, because, by definition, $t_{1} \geq 1$ (see Proposition 2) and $\mu \delta<1$, a sufficient condition for the previous ICC to hold is that:

$9+7 \mu \delta-28(\mu \delta)^{\widehat{t_{2}}} \leq 0$.

Now, take a pre-entry period $t=\widehat{t_{1}}-k$, where $1 \leq k \leq \widehat{t_{1}}$. Making use of (44), and setting $q_{t}=1 / 4$ for all periods $\widehat{t_{1}}-k \leq t \leq \widehat{t_{1}}-1$, one obtains the following ICC for the pre-entry period $\widehat{t_{1}}-k$ :

$$
\begin{aligned}
& \frac{9}{64} \mu^{\widehat{t_{1}}-k}-\frac{1}{8} \frac{(\mu \delta)^{\widehat{t_{1}}-k}-(\mu \delta)^{\widehat{\widehat{1}}}}{\delta^{\widehat{t_{1}}-k}(1-\mu \delta)} \leq \frac{1}{12} \frac{\mu^{\widehat{1_{1}}} \delta^{k}}{1-\mu \delta} \\
& -\left(\frac{1}{9} \frac{(\mu \delta)^{\widehat{\hat{t}_{1}}-k+1}-(\mu \delta)^{\widehat{\widehat{1}}-k+\widehat{\hat{t}_{2}}}}{\delta^{\widehat{1_{1}}-k}(1-\mu \delta)}+\frac{1}{16} \frac{\mu^{\widehat{\mathbb{1}_{1}}-k+\widehat{t_{2}}} \delta^{\widehat{\widehat{2}}}}{1-\mu \delta}\right) .
\end{aligned}
$$

Multiplying both sides of the previous ICC by $\delta^{\widehat{1}_{1}-k}(1-\mu \delta)$, and after some rearranging, the previous ICC can be re-written as follows:

$$
\frac{(\mu \delta)^{\widehat{1}_{1}-k}}{576}\left(9-17 \mu \delta+24(\mu \delta)^{k}-28(\mu \delta)^{\hat{2}_{2}}\right) \leq 0 .
$$

So, in order for the previous ICC to hold, it is sufficient that the following condition is satisfied:

$$
\begin{aligned}
& 9-17 \mu \delta+24(\mu \delta)^{k}-28(\mu \delta)^{\hat{f}_{2}}=\left(9+7 \mu \delta-28(\mu \delta)^{\widehat{T}_{2}}\right) \\
& \quad-24 \mu \delta\left(1-(\mu \delta)^{k-1}\right) \leq 0 .
\end{aligned}
$$


So, clearly, if condition (C3) holds, condition (C6) holds as well (remember that $\mu \delta<1$ ). This implies that the ICC in period $\widehat{t_{1}}-1$ is the binding pre-entry ICC.

\section{C.2 Proof of Proposition 3}

Making use of (44), some algebra shows that the ICC in period $t=\widehat{t_{1}}-1$ can be written as follows:

$$
\frac{\left(3 q_{t}-1\right)^{2}}{4} \mu^{\widehat{t_{1}}-1} \leq \frac{1}{12} \frac{\mu^{\widehat{t_{1}}} \delta}{1-\mu \delta}-\left(\frac{1}{9} \frac{(\mu \delta)^{\widehat{T_{1}}}-(\mu \delta)^{\widehat{\hat{F}_{1}}+\widehat{t_{2}}-1}}{\delta^{\widehat{t_{1}}-1}(1-\mu \delta)}+\frac{1}{16} \frac{\mu^{\widehat{t_{1}}-1+\widehat{t_{2}}} \delta^{\widehat{t_{2}}}}{1-\mu \delta}\right) .
$$

Now, from (42), it is clear that collusion possibilities are enhanced when $\widehat{t_{1}}$ increases and when $\widehat{t_{2}}$ decreases. When $\widehat{t_{1}}$ increases, the l.h.s. of the ICC (42) increases whereas the r.h.s is not affected. With an increase in $\widehat{t_{1}}$, there will be an increase in the number of periods in which the incumbent firms earn the pre-entry most collusive duopoly profit and, therefore, also a decrease in the number of periods in which they earn the most collusive triopoly profits. This effect contributes to an increase in the extent of collusion which can be sustained pre-entry, simply because it increases the continuation value of collusion at every period preentry. On the other hand, when $\widehat{t_{2}}$ decreases, the r.h.s of the ICC (42) decreases whereas the 1.h.s. is not affected. With a decrease in $\widehat{t_{2}}$, we will have a shorter first phase of the punishment in which firms earn the Cournot duopoly profits in each period and a longer second phase of the punishment in which firms earn the Cournot triopoly profits in each period: the punishment becomes harsher which contributes to an increase in the maximal level of pre-entry sustainable collusion.

Notice that from Proposition 2 and Lemma 1, one has that $\widehat{t_{i}} \in$ $\left\{\left\lfloor t_{i}\right\rfloor,\left\lceil t_{i}\right\rceil\right\}$ and $\left|t_{i}-\widehat{t_{i}}\right| \leq 1$, for $i=1,2$. Now, in order to avoid integer problems and because we are looking for a sufficient condition such that no collusion can be sustained as a MCTSEE in any period $t<\widehat{t_{1}}$, in what follows, let us focus on the (extreme case) values of $\widehat{t_{1}}$ and $\widehat{t_{2}}$ that most facilitate collusion possibilities. Formally, let $\widehat{t_{1}}=t_{1}+1$ and $\widehat{t_{2}}=t_{2}-1$, where $t_{1}$ and $t_{2}$ are, respectively, given by equations (18) and (32). When this is the case, the previous ICC can be rewritten as follows:

$$
\frac{\left(1-3 q_{t}\right)^{2}}{4} \mu^{t_{1}} \leq \frac{1}{12} \frac{\mu^{t_{1}+1} \delta}{1-\mu \delta}-\left(\frac{1}{9} \frac{(\mu \delta)^{t_{1}+1}-(\mu \delta)^{t_{1}+t_{2}-1}}{\delta^{t_{1}}(1-\mu \delta)}+\frac{1}{16} \frac{\mu^{t_{1}+t_{2}-1} \delta^{t_{2}-1}}{1-\mu \delta}\right) .
$$


Multiplying both sides of the previous ICC by $\delta^{t_{1}}(1-\mu \delta)$, and after some rearranging, one obtains:

$$
\frac{\left(1-3 q_{t}\right)^{2}}{4} \delta^{t_{1}}(1-\mu \delta) \mu^{t_{1}} \leq-\frac{(\mu \delta)^{t_{1}+1}}{144}\left(4-7(\mu \delta)^{t_{2}-2}\right) .
$$

Now, because, by definition, $t_{1} \geq 1$ (see Proposition 2 ), $\mu \delta<1$ and $q_{t} \in[1 / 4,1 / 3)$, the previous ICC will not hold if $g(\mu, \delta)>0$, where:

$$
g(\mu, \delta)=4-7(\mu \delta)^{t_{2}-2} .
$$

The rest of this proof identifies conditions under which $g(\mu, \delta)>0$. This will be done in three steps.

Step 1. Show that $\lim _{\delta \rightarrow 1 / \mu} g(\mu, \delta)<0$.

As a preliminary remark, notice that because $\mu \delta<1$, one must have that $\delta<1 / \mu$.

Now, let us start by computing the limiting value of the optimal entry time off the equilibrium path:

$$
\begin{aligned}
t_{2}^{*} & \equiv \lim _{\delta \rightarrow 1 / \mu} t_{2}=\frac{1}{\ln \mu} \lim _{\delta \rightarrow 1 / \mu}\left(\ln \left(\frac{\ln \delta^{16 K(1-\delta \mu)}}{\ln \delta \mu}\right)\right) \\
& =\frac{\ln 16+\ln \left(-K \ln \frac{1}{\mu}\right)}{\ln \mu} \geq 1 .
\end{aligned}
$$

where the last equality comes from the application of the l'Hôpital's rule. Now, making use of equations (C10) and (C11), it is straightforward to conclude that $\lim _{\delta \rightarrow 1 / \mu} g(\mu, \delta)=-3<0$.

Step 2. Show that $\lim _{\delta \rightarrow 4 /(7 \mu)} g(\mu, \delta)>0$.

Notice first that we are focusing attention on the case in which perfect collusion can be sustained ex post entry, $\mu \delta>4 / 7$ (Corollary 1 ), which in turn implies that $\delta>4 /(7 \mu)$. Now,

$\lim _{\delta \rightarrow 4 /(7 \mu)} g(\mu, \delta)=4-7\left(\frac{4}{7}\right)^{t^{*}-2}$

So, in order for $\lim _{\delta \rightarrow 4 /(7 \mu)} g(\mu, \delta)>0$, one must have that $t_{2}^{*}>3$ and this will be true if $K>\mu^{2} \tilde{K}$, where $\tilde{K}$ is given by equation (38).

Step 3. Apply the intermediate value theorem

Fix a value of $\mu>1$. Because the function $g(\mu, \delta)$ is continuous in $\delta$ for all $\delta \in[4 /(7 \mu), 1 / \mu)$ and $\lim _{\delta \rightarrow 4 /(7 \mu)} g(\mu, \delta)>0, \lim _{\delta \rightarrow 1 / \mu} g(\mu, \delta)<0$ then the equation $g(\mu, \delta)=0$ for some $\tilde{\delta} \in[4 /(7 \mu), 1 / \mu)$.

Thus, when $4 / 7 \leq \mu \delta \leq \mu \tilde{\delta}$, no $q_{t} \in[1 / 4,1 / 3)$ can be supported as a MCTSEE in period $t=\widehat{t_{1}}-1$. Now, in period $\widehat{t_{1}}-2$, firms anticipate 
that Cournot competition will take place in the following period independently of their choices in the current period. This implies that they will also play Cournot in period $\widehat{t_{1}}-2$. By backward induction, the same reasoning can be extended to the previous periods. So, collusion cannot be enforced as a MCTSEE in any period $t<\widehat{t_{1}}$. This completes the proof.

\section{C.3 Proof of Proposition 4}

Take the ICC in period $t=\widehat{t_{1}}-1$, given by equation (C7). Now, as explained in the proof of proposition 3, collusion possibilities are enhanced when $\widehat{t_{1}}$ increases and when $\widehat{t_{2}}$ decreases. Moreover, from Proposition 2 and Lemma 1, one has that $\widehat{t_{i}} \in\left\{\left\lfloor t_{i}\right\rfloor,\left\lceil t_{i}\right\rceil\right\}$ and $\left|t_{i}-\widehat{t}_{i}\right| \leq 1$, for $i=1,2$. Now, to avoid integer problems and because we are looking for a sufficient condition such that perfect collusion can be sustained as a MCTSEE in period $t=\widehat{t_{1}}-1$, in what follows, let us focus on the values of $\widehat{t_{1}}$ and $\widehat{t_{2}}$ that most hurt collusion possibilities. Formally, let $\widehat{t_{1}}=t_{1}-1$ and $\widehat{t_{2}}=t_{2}+1$, where $t_{1}$ and $t_{2}$ are, respectively, given by equations (18) and (32). When this is the case, the ICC (C7) can be written as follows:

$$
\begin{aligned}
\frac{\left(3 q_{t}-1\right)^{2}}{4} \mu^{t_{1}-2} \leq & \frac{1}{12} \frac{\delta \mu^{t_{1}-1}}{1-\mu \delta} \\
& -\left(\frac{1}{9} \frac{(\mu \delta)^{t_{1}-1}-(\mu \delta)^{t_{1}+t_{2}-1}}{\delta^{t_{1}-2}(1-\mu \delta)}+\frac{1}{16} \frac{\mu^{t_{1}+t_{2}-1} \delta^{t_{2}+1}}{1-\mu \delta}\right) .
\end{aligned}
$$

Notice as well that because we are looking for the equilibrium in which there is perfect collusion both before and after entry, $q_{t}=$ $1 / 4$. Knowing this, multiplying both sides of the previous ICC by $\delta^{\hat{t}_{1}-2}(1-\mu \delta)$ and after some rearranging, one obtains that equation (C13) is equivalent to:

$$
\frac{(\mu \delta)^{t_{1}-1}}{576}\left(7+9(\mu \delta)^{-1}-28(\mu \delta)^{t_{2}}\right) \leq 0 .
$$

Now, because, by definition, $t_{1} \geq 1$ (see Proposition 2 ), the previous ICC will hold if $f(\mu, \delta)<0$, where

$$
f(\mu, \delta)=7+9(\mu \delta)^{-1}-28(\mu \delta)^{t_{2}} .
$$

In the remaining of the proof, we look for conditions under which $f(\mu, \delta)<0$. This will be done in three steps.

Step 1. Show that $\lim _{\delta \rightarrow 1 / \mu} f(\mu, \delta)<0$.

Notice that because $\mu \delta<1$, one must have that $\delta<1 / \mu$. Moreover, and as shown in the proof of Proposition $3, t_{2}^{*} \equiv \lim _{\delta \rightarrow 1 / \mu} t_{2} \geq 1$ (see 
equation (C11)). So, making use of equations (C11) and (C15), it is straightforward to conclude that $\lim _{\delta \rightarrow 1 / \mu} f(\mu, \delta)=-12<0$.

Step 2. Show that $\lim _{\delta \rightarrow 4 /(7 \mu)} f(\mu, \delta)>0$.

We are assuming that perfect collusion can be sustained after entry, $\mu \delta>4 / 7$ (Corollary 1 ), which in turn implies that $\delta>4 /(7 \mu)$. Now,

$$
\lim _{\delta \rightarrow 4 /(7 \mu)} f(\mu, \delta)=\frac{91}{4}-16\left(\frac{4}{7}\right)^{t_{2}^{*}} .
$$

Now, because $t_{2}^{*} \geq 1$ (see equation (C11)), the previous inequality always holds.

\section{Step 3. Apply the intermediate value theorem}

Fix a value of $\mu>1$. Because the function $f(\mu, \delta)$ is continuous in $\delta$ for all $\delta \in[4 /(7 \mu), 1 / \mu)$ and $\lim _{\delta \rightarrow 4 /(7 \mu)} f(\mu, \delta)>0, \lim _{\delta \rightarrow 1 / \mu} f(\mu, \delta)<0$ then the equation $f(\mu, \delta)=0$ for some $\delta^{*} \in[4 /(7 \mu), 1 / \mu)$.

Thus, when $\mu \delta>\mu \delta^{*} \geq 4 / 7$, perfect collusion can be sustained as a MCTSEE both after entry and also in the period immediately before entry takes place (period $\widehat{t_{1}}-1$ ). Now, applying Lemma 2, it is straightforward to conclude that when $\mu \delta>\mu \delta^{*} \geq 4 / 7$, perfect collusion can be sustained as a MCTSEE in any period before entry. This completes the proof.

\section{References}

Abreu, D., 1986, "Extremal Equilibria of Oligopolistic Supergames," Journal of Economic Theory, 39, 191-225.

_ 1988, "On the Theory of Infinitely Repeated Games with Discounting," Econometrica, 56(2), 383-396.

Aubert, C., P. Rey, and W. Kovacic, 2006, "The Impact of Leniency and Whistle-Blowing Programs on Cartels," International Journal of Industrial Organization, 24(6), 12411266.

Besanko, D., D. Dranove, M. Shanley, and S. Schaefer, 2004, Economics of Strategy, (3rd Edition), New York: John Wiley \& Sons.

Capuano, C., 2002, "Demand Growth, Entry and Collusion Sustainability," Fondazione Eni Enrico Mattei, Nota di Lavoro 62. 2002.

Friedman, J.W., 1971, “A Non cooperative Equilibrium for Supergames," Review of Economic Studies, 28, 1-12.

— and J.-F. Thisse, 1994, "Sustainable Collusion in Oligopoly with Free Entry," European Economic Review, 38, 271-283.

Garrod, D., S. Megregian, O. Steffens, and J. Winterscheid, 2002, "Recent Airtours/First Choice EU Merger Decision," McDermott Will \& Emery Newsletter (June 2002). Available at http://www.mwe.com/index.cfm/fuseaction/publications.home/index.cfm.

Green, E.J. and R.H. Porter, 1984, "Noncooperative Collusion under Imperfect Price Information," Econometrica, 52, 87-100. 
Harrington, J.E., Jr., 1989, “Collusion and Predation Under (Almost) Free Entry," International Journal of Industrial Organization, 7, 381-401.

—_ 1991, "The Joint Profit Maximum as a Free-Entry Equilibrium Outcome," European Economic Review, 35, 1087-1101.

_ 2008, "Optimal Corporate Leniency Programs," Journal of Industrial Economics, 56, $215-246$.

— 2006, "How do Cartels Operate?," Foundations and Trends in Microeconomics, 2(1), $1-105$.

Ivaldi, M., B. Jullien, P. Rey, P. Seabright, and J. Tirole, 2003, “The Economics of Tacit Collusion," Report for the DG Competition-European Commission. Available at http://www.idei.asso.fr/English/ECv/CvChercheurs/EcvRey.html.

Martin, S., 1990, “Fringe Size and Cartel Stability," European University Institute, Working Paper ECO No. 90/16.

Motta, M., 2004, Competition Policy: Theory and Practice, Cambridge, UK: Cambridge University Press, $616 \mathrm{pp}$.

— and M. Polo, 2003, "Leniency Programs and Cartel Prosecution," International Journal of Industrial Organization, 21, 347-379.

Rotemberg, J. and G. Saloner, 1986, "A Supergame-Theoretic Model of Business Cycles and Price-Wars during Booms," American Economic Review, 76, 390-407.

Shaffer, S., 1995, "Stable Cartels with a Cournot Fringe," Southern Economic Journal 61, 744-754.

Tirole, J., 1988, The Theory of Industrial Organization, Cambridge, MA: The MIT Press, 479 pp.

Vasconcelos, H., 2004, "Entry Effects on Cartel Stability and the Joint Executive Committee," Review of Industrial Organization, 24, 219-241. 